\title{
Antineurogenic phenotypes induced by truncated Notch proteins indicate a role in signal transduction and may point to a novel function for Notch in nuclei
}

\author{
Toby Lieber, ${ }^{1}$ Simon Kidd, ${ }^{1}$ Elizabeth Alcamo, ${ }^{1,2}$ Victoria Corbin,, ${ }^{1,3}$ and Michael W. Young ${ }^{1,2}$ \\ ${ }^{1}$ Laboratory of Genetics, The Rockefeller University; ${ }^{2}$ Howard Hughes Medical Institute, New York, New York 10021 USA
}

\begin{abstract}
Loss of any one of several neurogenic genes of Drosophila results in overproduction of embryonic neuroblasts at the expense of epidermoblasts. In this paper a variety of altered Notch proteins are expressed in transgenic flies. Dominant lethal, antineurogenic phenotypes were produced by expression of three classes of mutant proteins: (1) a protein comprised of the cytoplasmic domain of Notch and devoid of sequences permitting membrane association; (2) a transmembrane protein lacking the extracellular, lin12/Notch repeats; and (3) transmembrane proteins carrying amino acid substitutions replacing one or both extracellular cysteines thought to be involved in Notch dimerization. These Notch proteins not only suppress the neural hypertrophy observed in Notch ${ }^{-}$embryos, but also generate a phenotype in which elements of the embryonic nervous system are underproduced. Action of the intracellular cdc10 repeats appears to be essential for wild-type Notch function or for the antineurogenic activity of these proteins. The activities of the dominant, gain-of-function proteins indicate that Notch functions as a signal transducing receptor during ectoderm development. Production of antineurogenic Notch proteins in embryos deficient for the other neurogenic genes allowed functional dependencies to be established. Delta, mastermind, bigbrain, and neuralized appear to function in elaboration of a signal upstream of Notch. Genes of the Enhancer of split complex act after Notch. The cytoplasmic domain of Notch contains nuclear localization sequences that function in cultured cells, and one of the Notch antineurogenic proteins, the cytoplasmic domain, accumulates in nuclei in vivo.
\end{abstract}

[Key Words: Antineurogenic phenotype; Notch protein; signal transduction; nuclear localization sequences]

Received June 23, 1993; revised version accepted August 4, 1993.

During development neuroblasts segregate from epidermal cells within the ectoderm. In Drosophila, at least two opposing classes of genes control the fate of these cells. One class, the proneural genes, as exemplified by genes of the achaete-scute complex (AS-C), appear to bestow the potential to become a neuroblast. Loss of function of any proneural gene results in a failure to form neuroblasts in some regions of the embryo and larva. Consequently, gaps form in the embryonic central nervous system (CNS), and elements of the peripheral nervous system (PNS) of the embryo are lost (Jimenez and Campos-Ortega 1979, 1990; Martin-Bermudo et al. 1991; Ghysen et al. 1993). The second class, the so-called neurogenic genes (named for the mutant phenotypes by which they were originally identified) appear to determine whether a cell having the potential to form a neu-

${ }^{3}$ Present address: Department of Physiology and Cell Biology, University of Kansas, Lawrence, Kansas 66045 USA. roblast will differentiate as a neuroblast or an epidermoblast. Null mutations of the neurogenic genes cause overproduction of neuroblasts at the expense of epidermoblasts. Mutant embryos show loss of epidermis and hypertrophy of the CNS and PNS (Lehmann et al. 1983; Hartenstein and Campos-Ortega 1986; Greenwald and Rubin 1992; Ghysen et al. 1993). It has been proposed that the neurogenic genes function through a pathway of lateral inhibition whereby only one of several equipotential cells (an equivalence group) established by the proneural genes will actually become a neuroblast (Simpson 1990; Simpson and Carteret 1990; Ghysen et al. 1993).

It has been determined recently that each of the neurogenic genes plays a related role in cell fate specification in the Drosophila mesoderm and endoderm /Corbin et al. 1991; Ruohola et al. 1991; Hartenstein et al. 1992; Xu et al. 1992). These results indicate that the neurogenic genes probably work together to form a molecular pathway that is used to determine cell fates in different germ layers. 
Notch, a member of the neurogenic gene family, encodes a large transmembrane protein (Johansen et al. 1989; Kidd et al. 1989). The extracellular domain of Notch, 1700 amino acids, includes 36 tandem epidermal growth factor (EGF)-like elements followed by three tandem repeats of a second cysteine-rich element (lin $12 /$ Notch elements) (Wharton et al. 1985; Kidd et al. 1986). The Notch cytoplasmic domain is $\sim 900$ amino acids and contains six tandem elements (cdc10- or ank- repeats) (Wharton et al. 1985; Kidd et al. 1986) similar to repeated sequences that promote protein-protein interactions in a variety of distantly related organisms (e.g., Kidd 1992). In addition, there is a polyglutamine (strep/opa) sequence and a putative PEST sequence (Wharton et al. 1985; Kidd et al. 1986).

Genetic mosaic studies have demonstrated that Notch acts autonomously; it must be expressed by a cell for that cell to develop as an epidermoblast. This is consistent with a role for Notch as a receptor (Hoppe and Greenspan 1986, 1990; Celis et al. 1991a; Heitzler and Simpson 1991). One possible ligand for Notch in vivo is Delta, another member of the neurogenic gene family. As with Notch, Delta is a transmembrane protein with EGF-like repeats (Vassin et al. 1987; Kopczynski et al. 1988; Haenlin et al. 1990). In vitro it has been demonstrated that Delta binds to EGF repeats 11 and 12 of Notch (Rebay et al. 1991), and mutations altering the structures of EGF-like elements of Notch and Delta modify this adhesion and interaction of the proteins in vivo (Brand and Campos-Ortega 1990; Lieber et al. 1992).

Genes encoding large transmembrane proteins resembling Notch have been reported in Caenorhabditis elegans, Xenopus, mouse, rat, and humans (Yochem et al. 1988; Yochem and Greenwald 1989; Coffman et al. 1990; Ellisen et al. 1991; Weinmaster et al. 1991, 1992; Franco del Amo et al. 1992; Jhappan et al. 1992; Robbins et al. 1992; Stifani et al. 1992; Kopan and Weintraub 1993). The discovery of Notch-like genes in distantly related organisms, and evidence for interdependent activity of all the neurogenic genes in different germ layers of Drosophila, indicates an ancient and central role for these proteins in eukaryotic cell differentiation.

To better understand the role of Notch in regulating cell fate, we have constructed strains of transgenic Drosophila that express a variety of incomplete Notch proteins. Striking, antineurogenic phenotypes (underproduction of neuroblasts) were generated by production of sequences composing only the intracellular domain of
Notch, and by expressing transmembrane Notch proteins that are deficient for certain extracellular sequences. Some of the truncated Notch proteins are active in the absence of putative ligands such as Delta. For Drosophila expressing the intracellular domain of Notch untethered to the membrane, immunocytochemistry indicates that the protein can be found in nuclei, possibly linking this protein's strong antineurogenic effects to a signal transducing function in the nucleus.

\section{Results \\ Construction of transgenes producing novel Notch proteins}

Deletions and point mutations of Notch coding sequences were fused to an $h s p 70$ promoter (Fig. 1) and moved into flies by P-element-mediated transformation. In our analysis we concentrated on embryonic phenotypes resulting from expression of altered Notch proteins in both mutant $\left(N^{-}\right)$and wild type backgrounds. Because Notch function is required for formation of any ventral cuticle (Lehmann et al. 1983), initially, we tested the ability of each altered Notch protein to rescue the cuticle phenotype of $\mathrm{N}^{-}$embryos. If expression of a novel Notch protein can promote cuticle production, the protein must supply functional activity in the transgenic embryo. We also assayed the effect of expressing each protein in a $\mathrm{N}^{+}$background, using anti-horseradish peroxidase (HRP) antisera to examine the CNS. If expression of a transgene produces abnormalities in the CNS, the novel Notch protein also must have some function, although this function may be aberrant. The absence of CNS defects in $\mathrm{N}^{+}$embryos could be the result of complete loss of function for the altered protein, or the protein could have wild-type function in our assay or be able to function in conjunction with wild-type Notch.

\section{A Notch minigene provides Notch function in embryos}

The control in our experiments was a Notch minigene construct consisting of fused genomic and cDNA sequences, $\mathbf{N}^{\text {hsN }}$ (Fig. 1) (Lieber et al. 1992). Figure 1 also indicates the phenotypes associated with $\mathrm{N}^{+}$and $\mathrm{N}^{-}$ embryos carrying $\mathrm{N}^{\mathrm{hsN}}$. Figure $2 \mathrm{~B}$ illustrates the cuticle rescue associated with $\mathrm{N}^{\mathrm{hsN}}$ when expressed in $\mathrm{N}^{-} \mathrm{em}$ -

Figure 1. Results of expressing mutant Notch proteins in $N^{-}$and $N^{+}$backgrounds. The top line is a diagram of Notch. The open rectangles correspond to the 36 EGF-like repeats, the circles to the three lin $12 / \mathrm{N}$ repeats (LN), the solid rectangle to the transmembrane sequence, the ovals to the six cdc10 repeats, the square to the polyglutamine sequence (polyQ/opa), and the single rectangle at the carboxyl terminus to the putative PEST sequence. Two cysteines thought to mediate intermolecular dimer formation are depicted, as are two putative NLSs (nls1 and nls2; see text). The diagram is not to scale. Various constructs that were introduced into transgenic flies are listed at left, along with the amino acids deleted (in parentheses). The blank spaces in the diagrams represent regions deleted. (Phenotype in $N^{-}$) The ability of the mutant Notch proteins to rescue (R) the cuticle phenotype of $N^{-}$embryos (see text; Fig. 2); (NR) No rescue; (-) not determined. A cuticle rescue experiment was not performed on $\mathrm{N}^{\Delta \mathrm{LN} \text { rpts }}$ because these lines are male lethal. (Phenotype in $\mathrm{N}^{+}$) The CNS phenotype, as illustrated using anti-HRP antibody, resulting from expression of the mutant Notch proteins in a wild-type background. (0) CNS appeared normal; (N) neurogenic; $(A)$ antineurogenic. 
hsN

$\Delta I$ (1790-2648)

$\triangle C D C 10$ rpts (1790-2154)

$\triangle$ polyQ (2537-2572)

$\Delta B a m / R V(2157-2536)$

$\Delta C T(2573-2703)$

$\triangle E G F 1-36$ (59-1465)

$\triangle E G F$ 1-18 (58-754)

AEGF 19-36 (755-1464)

$\Delta L N$ rpts (1467-1644)

$c^{1693>S}$

$C^{1696>S}$

$C^{1693}>S, C^{1696}>S$

$\Delta$ (EGF 1-18 and LN rpts)

$\Delta$ (EGF $19-36$ and LN rpts)

$\Delta(L N$ rpts and I)

$\Delta(\mathbf{L N}$ and CDC10 rpts)

$\Delta(L N$ rpts and Bam/RV)

$C^{1693}>S$ and $\triangle C D C 10$ rpts

$\Delta$ (EGF and LN rpts)

Intracellular domain ( $\Delta 1-1789)$
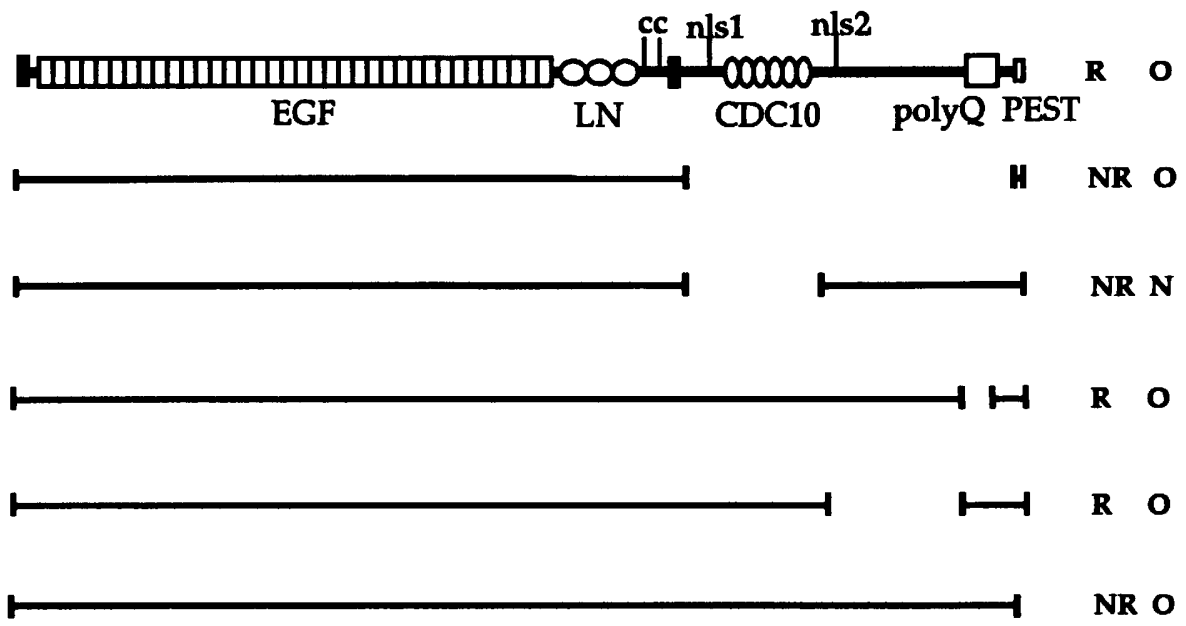

H

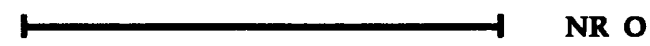

H
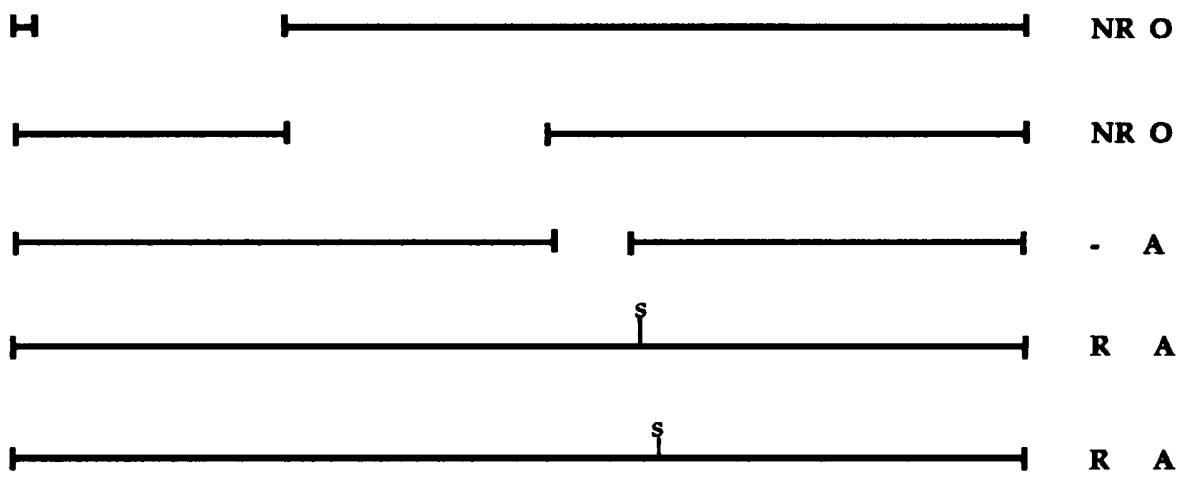

\$s

$\mathbf{R} \mathbf{A}$

M
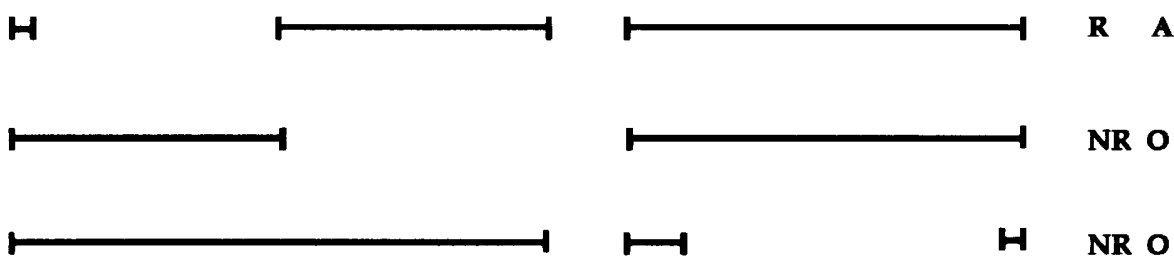

$\longmapsto$

H NR O
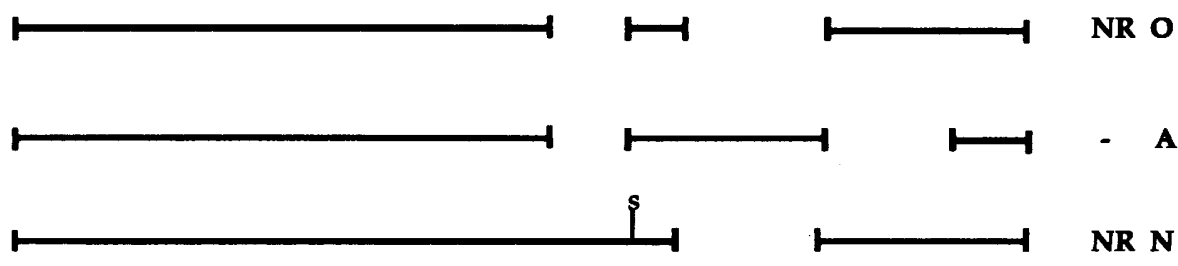

H
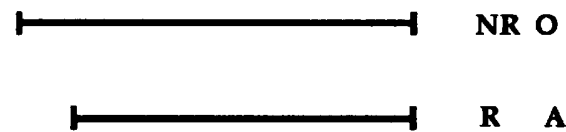

Figure 1. (See facing page for legend.) 
Figure 2. Cuticle rescue of $N^{-}$embryos by mutant Notch proteins. $(A)$ Ventral view of the cuticle of a wild-type embryo. $(B-H)$. Cuticle preparations of heatshocked embryos produced by crossing transgenic males to $w$ arm $^{\text {YD35 }} N^{X K 11} / F M 7$ (Hoppe and Greenspan 1990) females. The presence of the mirror-image duplications of the denticle belts in the ventral cuticle characteristic of $\mathrm{arm}$ indicates that the transgenic Notch proteins are allowing production of cuticle in arm $N / Y$ embryos. Cuticle rescue is pronounced on the posterior-ventral surface of all transgenic embryos. (B) Embryos produced by crossing $\mathrm{N}^{\text {hsN }}$ males to arm $N / F M 7$ females. $(C)$ Embryos produced by crossing $\mathrm{N}^{\Delta \text { polyQ }}$ males to arm N/FM7 females. (D) Embryos produced by crossing $\mathrm{N}^{\triangle \mathrm{BAM} / \mathrm{RV}}$ males to arm N/FM7 females. (E) Embryos produced by crossing $\mathrm{N}^{\text {c1693>s }}$ males to arm N/FM7 females. $(F)$ Embryos produced by crossing $\mathrm{N}^{\mathrm{c} 1696>\mathrm{s}}$ males to arm N/FM7 females. $(G)$ Embryos produced by crossing $\mathrm{N}^{\mathrm{c} 1693>\mathrm{s}, \mathrm{c} 1696>\mathrm{s}}$ males to $\mathrm{arm} N / F M 7 \mathrm{fe}-$ males. (H) Embryos produced by crossing $\mathrm{N}^{\Delta(E G F 1-18 \text { and LN rpts })}$ males to arm N/FM7 females.
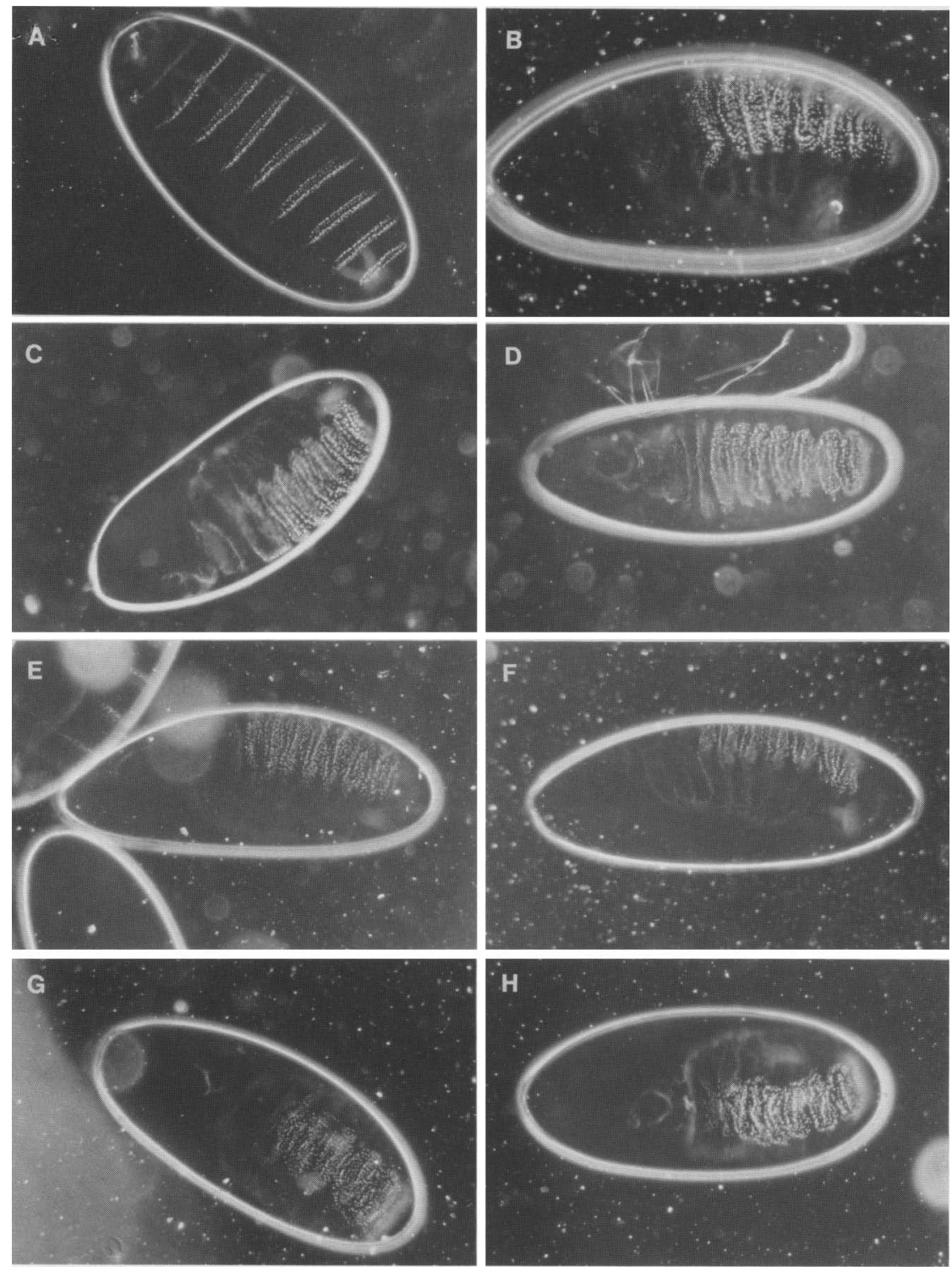

bryos. As shown, induction of $\mathrm{N}^{\text {hsN }}$ was performed in arm ${ }^{Y D 35} N^{X K 11}$ embryos. As $N^{X K 11}$ is a Notch null allele (Hoppe and Greenspan 1990), no ventral cuticle is produced in embryos homozygous or hemizygous for $N^{\text {XK11 }}$ (see also Hoppe and Greenspan 1986). These $N^{-}$embryos carry the recessive mutation armadillo (arm), which when homozygous or hemizygous causes mirrorimage duplications of the ventral denticle belts (Wieschaus et al. 1984; Weischaus and Riggleman 1987). The presence of cuticle characteristic of arm indicates that the cuticle was produced in arm $N / Y$ embryos and that it is the result of expression of the transgenic proteins. In all cases the phenotype observed was identical to that of homoygous or hemizygous arm embryos (Wieschaus et al. 1984; Weischaus and Riggleman 1987), suggesting that when the transgenic proteins are able to rescue the cuticle phenotype of $N^{-}$embryos, the rescue is complete (see also legend to Fig. 2 and Materials and methods).
Figure $3 \mathrm{~A}$ shows the phenotype associated with $\mathrm{N}^{\text {hsN }}$ expression in $\mathrm{N}^{+}$embryos, as assayed by anti-HRP staining of the developing CNS. Overexpression of wild-type Notch protein from the minigene in a $\mathrm{N}^{+}$genetic background had no measurable effect on the development of the CNS, presumably because this protein has wild-type function.

\section{$A$ region encompassing the cdc10 repeats is essential for Notch function}

The first region that we examined in our study was the cytoplasmic domain of Notch. Five deletions were constructed (see Fig. 1). Notch proteins lacking only a region encompassing the cdc10 repeats $\left(\mathrm{N}^{\Delta \mathrm{CDClO}} \mathrm{rpts}\right)$ were unable to rescue the cuticle phenotype of $N^{-}$embryos (see Fig. 1). These results imply that cdc10 elements are critical for production of an epidermalizing activity by 


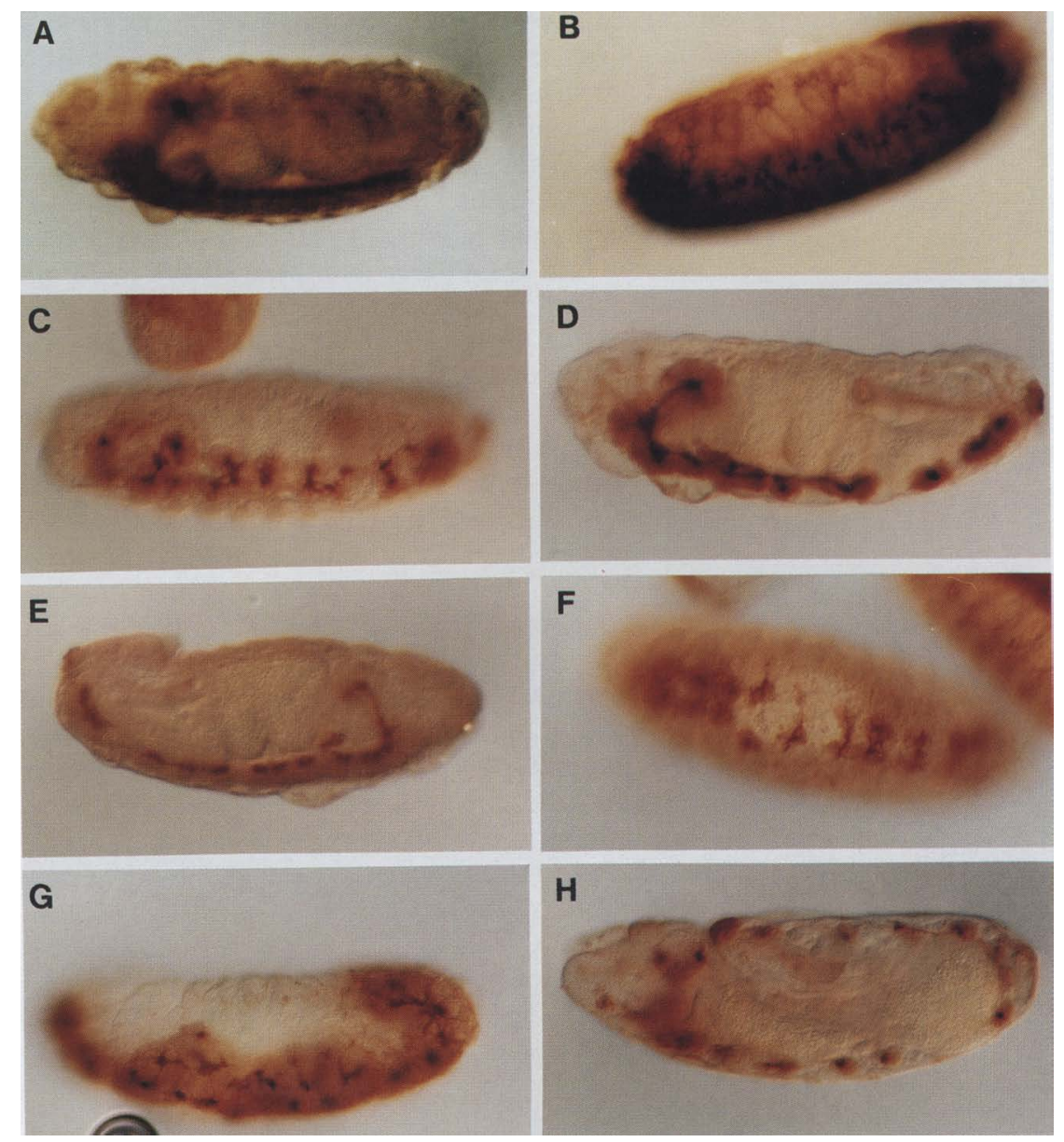

Figure 3. CNS phenotypes generated by expression of mutant Notch proteins in wild-type backgrounds. Transgenic embryos were heat-shocked, and their CNSs examined using anti-HRP antibody (see Materials and methods). All embryos are the same age. In lateral views, the ventral side is down. (A) Lateral view of an embryo expressing $\mathrm{N}^{\text {hsN }}$ (anterior is to the left). The CNS appears wild-type. $(B)$ Lateral view of an embryo expressing $\mathrm{N}^{\Delta \mathrm{CDC10} \text { rpts }}$ (anterior is to the right). The nervous system is hypertrophied. Compare with $A$ and the $N^{-}$embryo in Fig. 6A. $(C)$ Ventrolateral view of an embryo expressing $\mathrm{N}^{\mathrm{c} 1693>\mathrm{s}}$ (anterior is to the left.) Note the breaks in the ventral nerve cord indicative of an antineurogenic phenotype. $(D)$ Lateral view of an embryo expressing $\mathrm{N}^{\mathrm{c} 1696>\mathrm{s}}$ (anterior is to the left $t$. (E) Lateral view of an embryo expressing $\mathrm{N}^{\mathrm{cl} 1693>\mathrm{s}, \mathrm{cl} \text { 696>s }}$ (anterior is to the right). $(F)$ Ventral view of an embryo expressing $\mathrm{N}^{\Delta \mathrm{LN} \text { rpts }}$ (anterior is to the left). (G) Lateral view of an embryo expressing

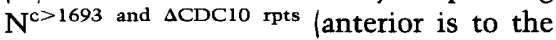
right). $(H)$ Lateral view of an embryo expressing $\mathrm{N}^{\text {Intracellular domain }}$ (anterior is to the left.)
Notch. We (T.L.) have preliminary evidence (results of testing only one line) that protein lacking the carboxyl terminus of Notch $\left(\mathrm{N}^{\Delta \mathrm{CT}}\right)$ is also unable to rescue the cuticle phenotype of $\mathrm{N}^{-}$embryos (data not shown). $\mathrm{N}^{\Delta C T}$ lacks only the carboxy-terminal 130 amino acids of Notch. This deletion includes the putative PEST sequence. Aside from 364 amino acids deleted by $\mathrm{N}^{\Delta C D C 10}$ rpts and 130 amino acids deleted by $\mathrm{N}^{\Delta \mathrm{CT}}$, the sequences in the cytoplasmic domain are either dispensable for function in embryos or are functionally redundant in the cuticle production assay, as Notch proteins deleted for the strep/opa (polyglutamine) repeats $\left(\mathrm{N}^{\Delta \text { polyQ}}\right)$, or for the region lying between the cdc10 repeats and the strep/opa repeats $\left(\mathrm{N}^{\triangle \mathrm{BAM} / \mathrm{RV}}\right)$, rescued the cuticle phenotype of $N^{-}$embryos (Figs. 1 and 2C,D).

$\mathrm{N}^{\Delta \mathrm{I}}, \mathrm{N}^{\Delta \mathrm{polyQ}}, \mathrm{N}^{\Delta \mathrm{BAM} / \mathrm{RV}}$, and $\mathrm{N}^{\Delta \mathrm{CT}}$ do not produce a phenotype when expressed in $\mathrm{N}^{+}$embryos (see Fig. 1), whereas $\mathrm{N}^{\Delta \mathrm{CDC} 10}$ rpts produces a strong neurogenic (dominant, loss-of-function) phenotype in $N^{+}$embryos (Figs. 1 and 3B). Possibly this protein is able to bind ligand (e.g., Delta) but is unable to transmit a signal. Thus, expression of this protein may result in the sequestering of ligand and a phenotype characteristic of loss of the ligand.

\section{EGF repeats are required for some} Notch proteins to function

We then examined the effect of deleting portions of the external domain of Notch. Expression of Notch proteins deleted for all EGF repeats (N $\left.{ }^{\triangle E G F} 1-36\right)$, EGF repeats $1-18\left(\mathrm{~N}^{\Delta \mathrm{EGF}}{ }^{1-18}\right)$, or EGF repeats $19-36\left(\mathrm{~N}^{\Delta \mathrm{EGF}}{ }^{19-36}\right)$ cannot rescue the cuticle phenotype of $N^{-}$embryos (Fig. 1). By this assay, the proteins are nonfunctional. The EGF repeats are therefore required for Notch proteins carrying all remaining sequences to function. In cell culture, an essential Delta-binding site in Notch has been mapped to EGF repeats 11 and 12 (Rebay et al. 1991). Notch-Delta interactions are also depressed in vitro by mutations in Notch EGF repeats 14 and 29 (Lieber et al. 1992). Because proteins containing EGF repeats 1-18 are functionless, perhaps for embryogenesis, EGF repeats 11 and 12 are not sufficient for functional Delta binding without the context provided by additional regions of the external domain of Notch, or the remainder of the EGF repeats could be required for receipt of any signal resulting from Delta binding. Alternatively, other ligands might interact with the additional EGF repeats, and may be required for receipt of any Notch-activating signal. 
None of the $\mathrm{N}^{\triangle \mathrm{EGF}}$ proteins produced a phenotype when expressed in a $N^{+}$background indicating that they do not interfere with wild-type Notch function (see Fig. 1).

The lin12/N repeats and cysteines 1693 and 1696 are required to maintain Notch in an inactive state

It has been postulated that Notch dimerization is mediated by cysteines 1693 and 1696 (Kidd et al. 1989). Notch proteins in which either or both of the cysteines were mutated to serines were able to rescue the cuticle phenotype of $N^{-}$embryos (Figs. 1 and 2E-G). If these cysteines are responsible for the observed dimerization, Notch does not need to exist as a dimer to function.

Interestingly, expression of $\mathrm{N}^{\mathrm{c1693>s}}, \mathrm{N}^{\mathrm{c} 1696>\mathrm{s}}$, or the double mutant ( $\mathrm{N}^{\mathrm{c} 1693>\mathrm{s}, \mathrm{cl} 1696>\mathrm{s}}$ ), or expression of the protein lacking the lin $12 / \mathrm{N}$ repeats $\left(\mathrm{N}^{\Delta \mathrm{LN} \text { rpts }}\right)$, resulted in a strong antineurogenic phenotype in $\mathrm{N}^{+}$embryos (Figs. 1 and 3C-F). Thus, all four altered Notch proteins produce a dominant gain of function. The antineurogenic phenotype produced by action of the modified Notch proteins is similar to that of embryos deficient for AS-C, which exhibit neural hypoplasia owing to both a lowered production of neuroblasts and an increased cell death at later stages (Jimenez and Campos-Ortega 1979, 1990). Therefore, the behavior of these antineurogenic Notch proteins is consistent with the postulated role for the neurogenic genes as repressors of the proneural genes (Brand and Campos-Ortega 1988; Cabrera 1990; Celis et al. 1991; Skeath and Carroll 1992; Ghysen et al. 1993; Ruiz-Gomez and Ghysen 1993).

The ability of each of the antineurogenic Notch proteins to function is dependent on the presence of the cdc10 repeats. In a doubly mutant Notch in which a deletion of most of the cytoplasmic domain or just a region encompassing the cdc10 repeats is superimposed on the antineurogenic mutation (e.g., $\mathrm{N}^{\mathrm{c} 1693>\mathrm{s} \text { and } \triangle C D C 10 \text { rpts }}$, there is no rescue of the cuticle phenotype of $\mathrm{N}^{-}$embryos (Fig. 1). Also, expression of these proteins in a $N^{+}$background no longer produces an antineurogenic phenotype. The doubly mutant proteins now produce a dominant neurogenic phenotype in $N^{+}$ embryos comparable with that observed after expression of $\mathrm{N}^{\Delta \mathrm{CDCl} 10} \mathrm{rpts}$ alone (Fig. 3, cf. B with G). Amino acids

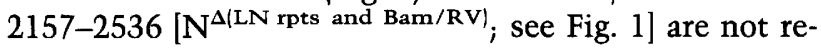
quired for manifestation of the antineurogenic phenotype, further indicating the central role played by cdc10 elements, both in provision of wild-type activity and in the dominant gain of function activity of these proteins.

\section{Expression of the intracellular domain of Notch results in an antineurogenic phenotype}

In other systems, receptors whose activities are independent of binding of their ligands have been generated by deletion of their extracellular, ligand-binding domains (Yarden and Ullrich 1988). For example, a gain-of-function sevenless mutation has been generated by overexpressing a truncated sevenless protein (Basler et al. 1991).
These constitutively active receptors contain their transmembrane and intracellular domains. To determine whether Notch behaves as such a receptor, we generated transformants expressing a truncated Notch protein deleted for the EGF and lin $12 / \mathrm{N}$ repeats [ $\mathrm{N}^{\Delta \text { (EGF and LN rpts)] }}$ This construct contained the Notch signal sequence, the cysteines postulated to be responsible for dimer formation, and the transmembrane and intracellular domains. This protein did not possess enough wild-type activity to allow for cuticle production in $N^{-}$embryos (summarized in Fig. 1). Expression of this protein in a wild-type background resulted in HRP patterns that were predominantly wild-type with some embryos that were very slightly antineurogenic (see Fig. 1). This phenotype was not in any way comparable with that generated by deletion of the lin $12 / \mathrm{N}$ repeats or mutation of cysteines 1693 and 1696.

Further truncation of Notch does result in constitutive activation. Expression of just the intracellular domain of Notch ( $\mathrm{N}^{\text {Intracellular domain }}$, Fig. 1$)$, in this case without the signal sequence, cysteines 1693 and 1696, and the transmembrane domain, was able to rescue cuticle production in $\mathrm{N}^{-}$embryos (see Fig. 1). Presumably, the cytoplasmic domain is able to carry out Notch function independently of any interactions mediated by the extracellular domain. Moreover, in a $\mathrm{N}^{+}$background, expression of the cytoplasmic domain of Notch resulted in a strong antineurogenic phenotype, comparable with that produced by $\mathrm{N}^{\mathrm{LN}}$ rpts and proteins with the described extracellular cysteine mutations (Figs. 1 and $3 \mathrm{H}$ ).

The cytoplasmic domain of Notch, untethered to the membrane, is found in nuclei

Three types of mutant Notch proteins generate antineurogenic phenotypes. Two of these, proteins lacking the cysteines thought to be involved in intermolecular disulfide bond formation between Notch proteins and proteins lacking the cysteine-rich lin $12 / \mathrm{N}$ repeats, would be expected to be localized, as with wild-type Notch, in the plasma membrane. In contrast, protein expressed by constructs containing only the cytoplasmic domain of Notch should not be associated with the membrane. Because the subcellular localization of this protein might give a clue as to how wild-type Notch functions, we examined the fate of $\mathrm{N}^{\text {Intracellular domain }} . N^{+}$larvae expressing $\mathrm{N}^{\text {Intracellular domain }}$ under $h s p 70$ control, were heat shocked, and their brains, salivary glands, and attached fat bodies were removed and reacted with an antibody directed against Notch cytoplasmic sequences (see Materials and methods). Surprisingly, $\mathrm{N}^{\text {Intracellular domain }}$ was found to be localized primarily in nuclei in all three tissues (Fig. 4B,E,F). Moreover, this protein does not accumulate to equal levels in all nuclei in the larval brain and ventral ganglion; the nuclei of neuroblasts [identified by their location (Truman and Bate 1988) and large size] accumulate $\mathrm{N}^{\text {Intracellular domain }}$ to higher levels than the surrounding cells. When expressed in cultured Drosophila cells, this protein is also localized to nuclei (Fig. 5,B,C). 

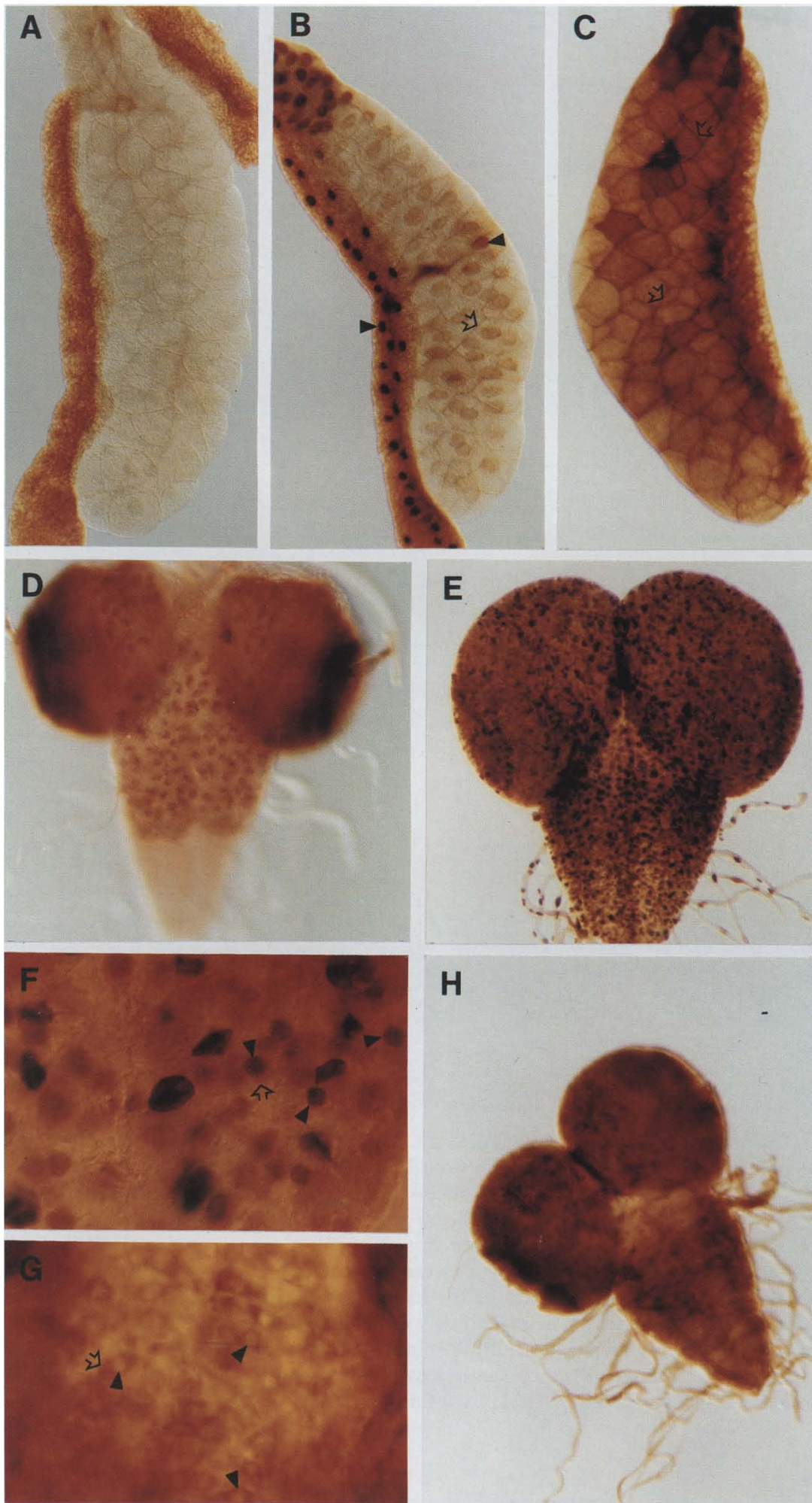

\section{E}

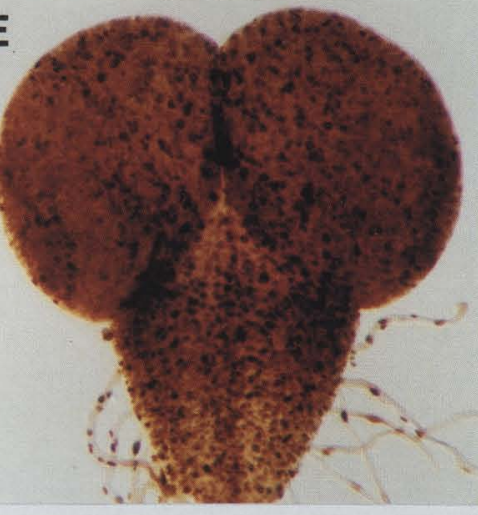

H

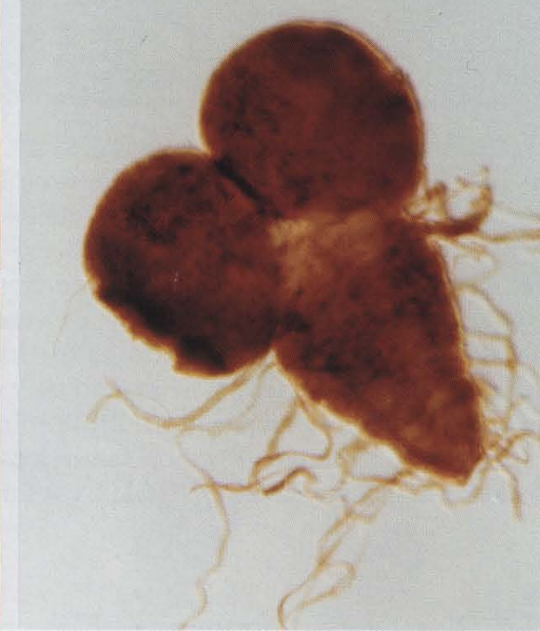

Figure 4. Immunocytochemical location of mutant Notch proteins in vivo. Notch proteins were detected as described previously using an antibody directed against amino acids $2115-2536$ of the cytoplasmic domain of Notch. $(A-C)$ Salivary glands and attached fat body; $(D, E$, and $H)$ brains and ventral ganglia; $(F, G)$ higher magnification views of thoracic ganglia stained with antiNotch antisera. $A$ and $D$ show tissue from $y w\left(N^{+}\right)$larvae; $B, E$, and $F$ are from yw $\left\langle N^{+}\right)$larvae transformed with constructs expressing the cytoplasmic domain untethered to the membrane ( $\left.\mathrm{N}^{\text {Intracellular domain }}\right) ;$ and $C, G, H$, are larval tissue transformed with $\mathrm{N}^{\Delta \mathrm{LN}}$ rpts. Solid arrowheads denote nuclei; open arrows indicate cell membranes. On the basis of size and location (Truman and Bate 1988), most of the nuclei in which the cytoplasmic domain of Notch accumulates to high levels in $E$ and $F$ are those of neuroblasts.
The nuclear localization of $\mathrm{N}^{\text {Intracellular domain }}$ might be the result of passive association with a nuclear protein: In the absence of membrane association for the altered Notch protein such a protein interaction might draw $\mathrm{N}^{\text {Intracellular domain }}$ into the nucleus. Alternatively, the cytoplasmic domain of Notch might contain functional nuclear localization signals (NLSs). To discriminate between these possibilities, constructs encoding various segments of the cytoplasmic domain of Notch (Fig. 5A) were expressed in cultured Drosophila cells, and the lo- 


\section{A}

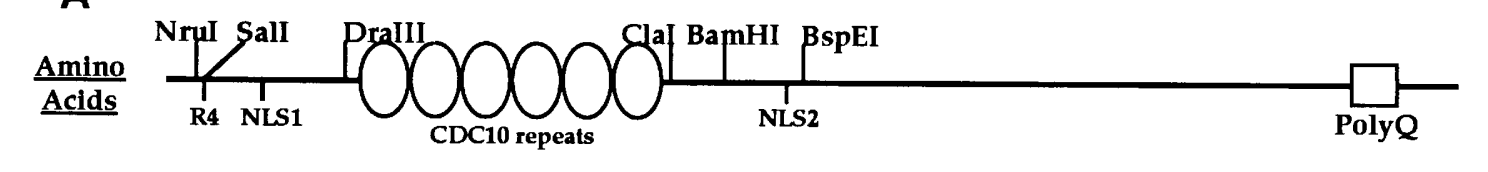

\section{Nuclear Localisation}

1788-2703

1772-1822

1806-1849

1788-1893

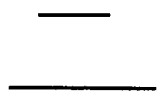

1895-2115

1795-2157

1895-2157

2157-2703

2157-2211

2211-2703
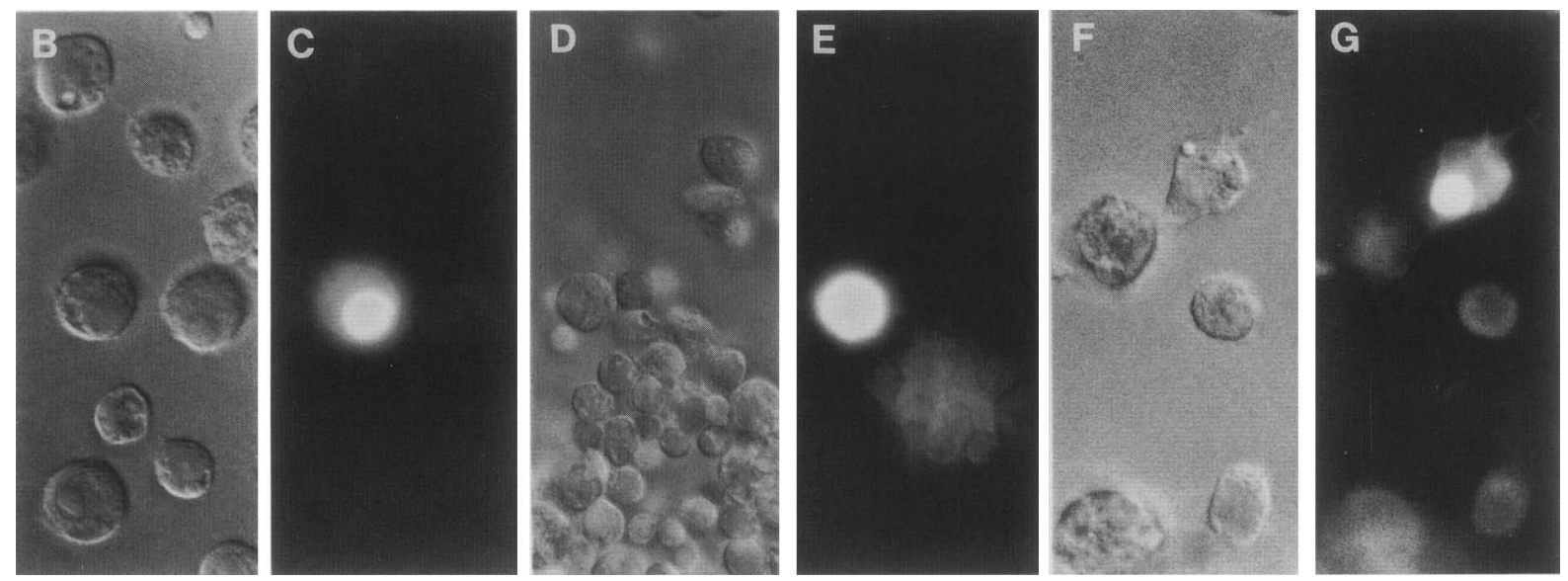

Figure 5. Mapping of NLSs in the cytoplasmic domain of Notch. (A) A diagram of the cytoplasmic domain of Notch showing the location of cdc10 repeats (ovals), the polyglutamine sequence (square), NLS-like sequences (NLS1 and NLS2), and a run of four arginine residues (R4). Two of the constructs, expressing amino acids 1772-1822 and 1806-1849, were generated by PCR; the remainder were constructed using the restriction sites shown above the diagram. Except for 1788-2703 and 1795-2157, all of the sequences were fused to the carboxyl terminus of $\beta$-gal under the control of the actin 5C promoter (Thummel et al. 1988). A monoclonal antibody against $\beta$-galactosidase was used to detect these fusion proteins. The remaining two sequences were fused to a cactus-flag construct described previously (Kidd 1992). Amino acids 1788-2703 were expressed under the control of the hsp70 promoter and amino acids 1795-2157 were expressed under the control of the actin promoter. These are detected by an antibody directed against amino acids 1795-2157 of Notch. (-) Cytoplasmic localization; (+) nuclear. (C) The nuclear localization of the soluble cytoplasmic domain of Notch (amino acids 1788-2703) in Schneider cells. $(B)$ The corresponding DIC image $;(E)$ cytoplasmic location of amino acids $1772-1822$ containing four arginines; $(D)$ DIC image of $E ;(G)$ Nuclear location of amino acids 2157-2211 containing NLS2; $(F)$ DIC image of $G$.

calizations of the proteins were determined. Localization was assessed either directly with antibody against the cytoplasmic domain of Notch or by ability to translocate the normally cytoplasmic $\beta$-galactosidase protein into the nucleus as Notch- $\beta$-galactosidase fusion protein (Fig. 5D-G; see also Materials and methods). Two short Notch segments (amino acids 1806-1849 and 21572211) were found to translocate $\beta$-galactosidase fusion proteins into the nucleus (Fig. 5F-G shows localization of N2157-2211). Inspection of the amino acid sequence of the two segments revealed that the first contains the sequence KRQR (amino acids 1832-1835), whereas the second has the sequence KKAK (amino acids 22022205). Both of these match the consensus for NLSs derived by Chelsky et al. (1989). The two sequences are depicted as NLS1 and NLS2 in Figure 5A. NLS2 corre- 
sponds to a part of the sequence identified by Stifani et al., (1992) as a putative bipartite NLS.

As described in an earlier section of this paper, two classes of altered Notch proteins in addition to the cytoplasmic domain ( $\mathrm{N}^{\text {Intracellular }}$ domain) generated antineurogenic phenotypes: a protein lacking the lin $12 / \mathrm{N}$ repeats $\left(\mathrm{N}^{\Delta L N \text { rpts}}\right)$ and Notch proteins mutated for one or both cysteines thought to be involved in intermolecular disulfide bond formation (Fig. 1). No evidence was found for the localization of either class of protein in nuclei (Fig. 4C,G-H shows results for $\mathrm{N}^{\Delta \mathrm{LN}}$ rpts). The Notchcytoplasmic-domain antibody stains $\mathrm{N}^{\Delta \mathrm{LN}}$ rpts-expressing larval brains uniformly (Fig. 4H). Closer examination reveals that this antigen is associated with cell membranes (Fig. 4G). Membrane association for $\mathrm{N}^{\Delta \mathrm{LN}}$ rpts is particularly clear in stained, third-instar larval salivary glands (Fig. $4 \mathrm{C}$ ). The $\mathrm{N}^{\Delta \mathrm{LN}}$ rpts protein also localizes to membranes in cultured Drosophila cells. Membrane lo- calization was observed as well in cultured cells for Notch proteins mutated at cysteine 1693, cysteine 1696, or both cysteines 1693 and 1696 (T. Lieber, unpubl.).

\section{The antineurogenic phenotypes do not depend} on coexpression of wild-type Notch

Anti-HRP antisera was used to examine the CNSs of $N^{-}$ embryos expressing the mutant Notch proteins. The $N$ allele used, $N^{264-47}$, behaves as a null mutation and produces an extreme neurogenic phenotype (Lehmann et al. 1983). As shown in Figure 6B, $N^{-}$embryos expressing the wild-type Notch minigene ( $\mathrm{N}^{\mathrm{hs}}$; Fig. 1) produce an essentially wild-type nervous system. Similarly, the nervous systems of $N^{-}$embryos expressing $\mathrm{N}^{\Delta \text { polyQ }}$ or $\mathrm{N}^{\triangle \mathrm{BAM} / \mathrm{RV}}$ (see Figs. 1 and $6 \mathrm{C}, \mathrm{D}$ ) appear normal.

Expression in $N^{-}$embryos of proteins lacking the $\operatorname{lin} 12 / \mathrm{N}$ repeats $\left(\mathrm{N}^{\Delta \mathrm{LN}}\right.$ rpts ; Fig. $6 \mathrm{E}$ ), or of proteins mu-
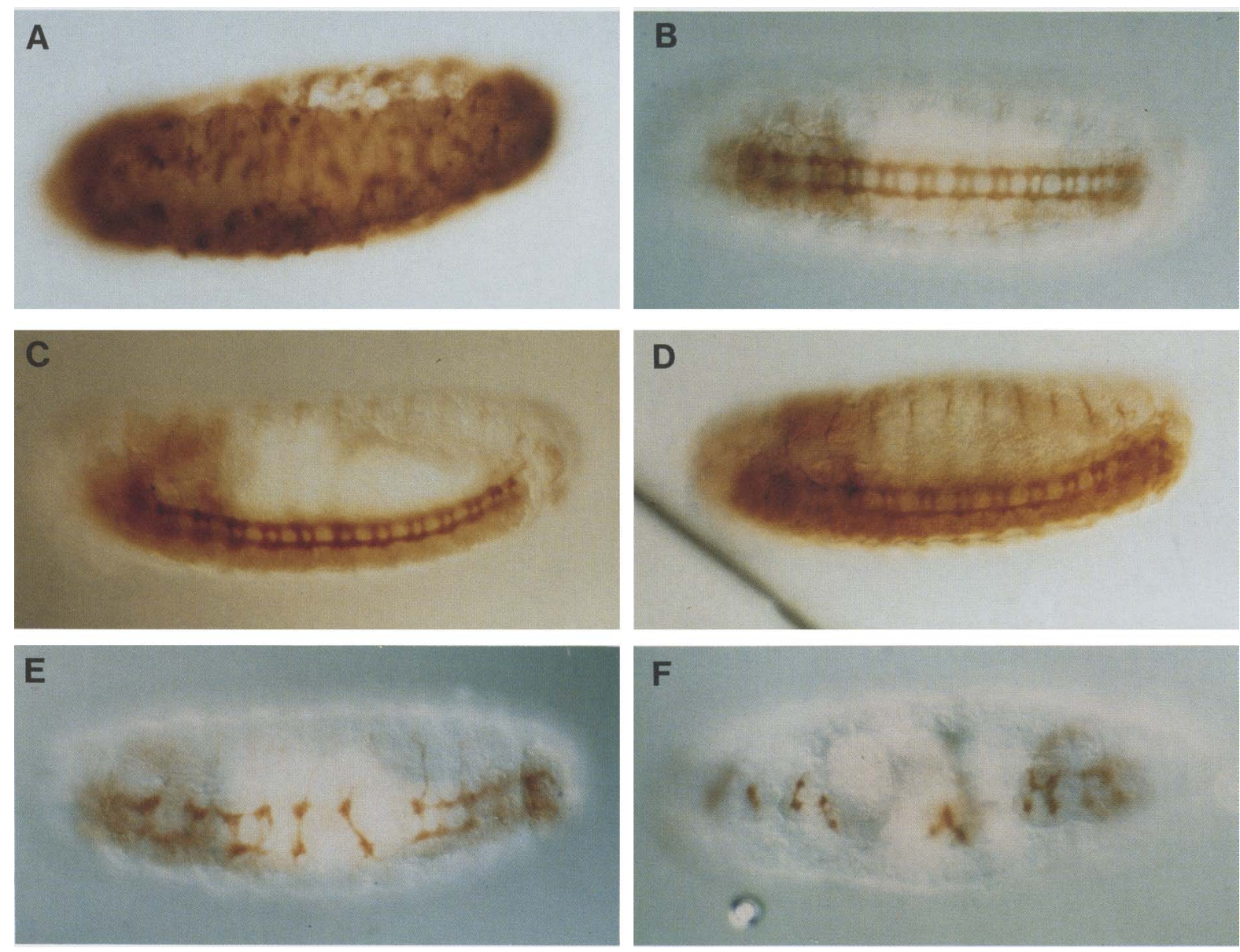

Figure 6. The antineurogenic phenotypes are independent of wild-type Notch. Transgenic flies expressing the mutant Notch proteins were crossed into a $N^{264-47} / F M 7$ lacZ (Lindsley and Zimm 1992) background. Heat-shocked embryos produced by these lines were double stained with anti- $\beta$-galactosidase and anti-HRP antibodies (see Materials and methods). Hemizygous $N^{-}$embryos were identified by the lack of reactivity with the anti- $\beta$-gal antibody. All the embryos shown are $N^{-}$. Anterior is to the left for all embryos. $(A)$ A ventral view of a $N^{264-47} / Y$ embryo. (B) A ventral view of a $N^{264-47} / Y$ embryo expressing $\mathrm{N}^{\mathrm{hsN}}$. The CNS appears normal as do the CNSs of $N^{264-47} / Y$ embryos expressing $\mathrm{N}^{\Delta \text { polyQ }}(C)$ and $\mathrm{N}^{\Delta \mathrm{BAM} / \mathrm{RV}}(D) .(E, F)$ The antineurogenic phenotype is still manifest in a $N^{264-47} / \mathrm{Y}$ background. $(E)$ An embryo expressing $\mathrm{N}^{\Delta \mathrm{LN} \text { rpts }} ;(F)$ an embryo expressing $\mathrm{N}^{\mathrm{c} 1693>\mathrm{s}}$. Compare with the antineurogenic phenotype observed in a $N^{+}$background (Fig. 3C-F). 
tated for either or both of the cysteines (e.g., $\mathrm{N}^{\text {c1693>s }}$; Fig. 6F) thought to be involved in dimer formation, results in an antineurogenic phenotype identical to that observed when these proteins were expressed in a $\mathrm{N}^{+}$ background (cf. Fig. $3 \mathrm{C}$ with $6 \mathrm{~F}$ and $3 \mathrm{~F}$ with $6 \mathrm{E}$ ). Eliminating or lowering the dose of wild-type Notch, therefore, has no effect on the manifestation of the antineurogenic phenotype: Embryos that would have shown a neurogenic phenotype are converted by expression of the transgene to antineurogenic. Therefore, these mutant Notch proteins are not simply hypermorphic; rather, they must have altered function. The results also indicate that the antineurogenic function of these truncated proteins does not depend on their association with, and activation of, wild-type Notch protein.

The antineurogenic phenotypes resulting from expression of the mutant Notch proteins differ in their dependence on other neurogenic gene products

We then examined whether the antineurogenic phenotypes were dependent on Delta. As Delta requires EGF repeats 11 and 12 for interaction with Notch in vitro (Rebay et al. 1991), the antineurogenic phenotype associated with expression of $N^{\text {Intracellular domain }}$ (Fig. 1) is presumably independent of Delta. Delta dependence of the $\operatorname{lin} 12 / \mathrm{N}$ repeat deletion was studied in two ways. First, we generated transformants carrying deletions for both the $\operatorname{lin} 12 / \mathrm{N}$ repeats and EGF repeats $1-18$

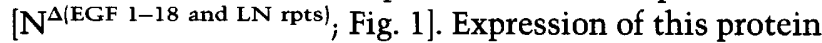
was able to rescue the cuticle phenotype of $N^{-}$embryos (see Fig. $2 \mathrm{H}$ ) and resulted in an antineurogenic phenotype in $\mathrm{N}^{+}$embryos (Figs. 1 and 7A). The function of this protein is therefore independent of the ligand Delta, if Notch EGF elements required for Delta binding in vitro are also required in vivo. Interestingly, expression of protein deleted for the lin $12 / \mathrm{N}$ repeats and EGF repeats 19$36\left[\mathrm{~N}^{\Delta(\mathrm{EGF} 19-36 \text { and } \mathrm{LN} \text { rpts)}]}\right.$ was neither able to rescue the cuticle phenotype of $N^{-}$embryos nor able to produce an antineurogenic phenotype in $\mathrm{N}^{+}$embryos (see Fig. 1). The same observation was made regarding protein deleted for all the EGF repeats and the $\operatorname{lin} 12 / \mathrm{N}$ repeats $\left[\mathrm{N}^{\Delta(\text { EGF } \text { and } L N \text { rpts) }}\right]$. This suggests that one or more EGF repeats numbered $19-36$, or the short Notch protein segment separating the EGF elements and the lin $12 / \mathrm{N}$ re-
Figure 7. Dependence of the antineurogenic phenotype on the neurogenic genes. $(A \mid \mathrm{A}$ wild-type embryo expressing $\mathrm{N}^{\Delta \mid \text { EGF } 1-18 \text { and } L N \text { rpts) }}$ stained with antiHRP antibody. $(B-E)$ Phenotypes resulting from expression of $\mathrm{N}^{\Delta \mathrm{LN}}$ rpts in various mutant backgrounds as depicted using anti-HRP antisera. Homozygous mutant embryos were identified by their lack of reactivity with anti- $\beta$-gal antibody (see Materials and methods). $(B)$ Expression of $\mathrm{N}^{\Delta \mathrm{LN} \text { rpts }}$ in a homozygous $D l^{X}$ background. (C) Expression of $\mathrm{N}^{\mathrm{\Delta LN} \text { rpts }}$ in $n e u^{I F 65}$. $(D)$ Expression of $\mathrm{N}^{\Delta \mathrm{LN}}$ rpts in $b i b^{A 5156}$. (E) Expression of $\mathrm{N}^{\Delta \mathrm{LN} \text { rpts in mamII113 }}$. (F) The antineurogenic phenotype produced by $\mathrm{N}^{\text {Intracellular domain }}$ is not observed in a homozygous $E(s p l)^{R 1}$ embryo. There is no suppression of the neurogenic phenotype. (G) A homozygous bib ${ }^{A 5156}$ embryo. $(H)$ $\mathrm{N}^{\mathrm{c} 1693>\mathrm{s}}$ in the bib background.
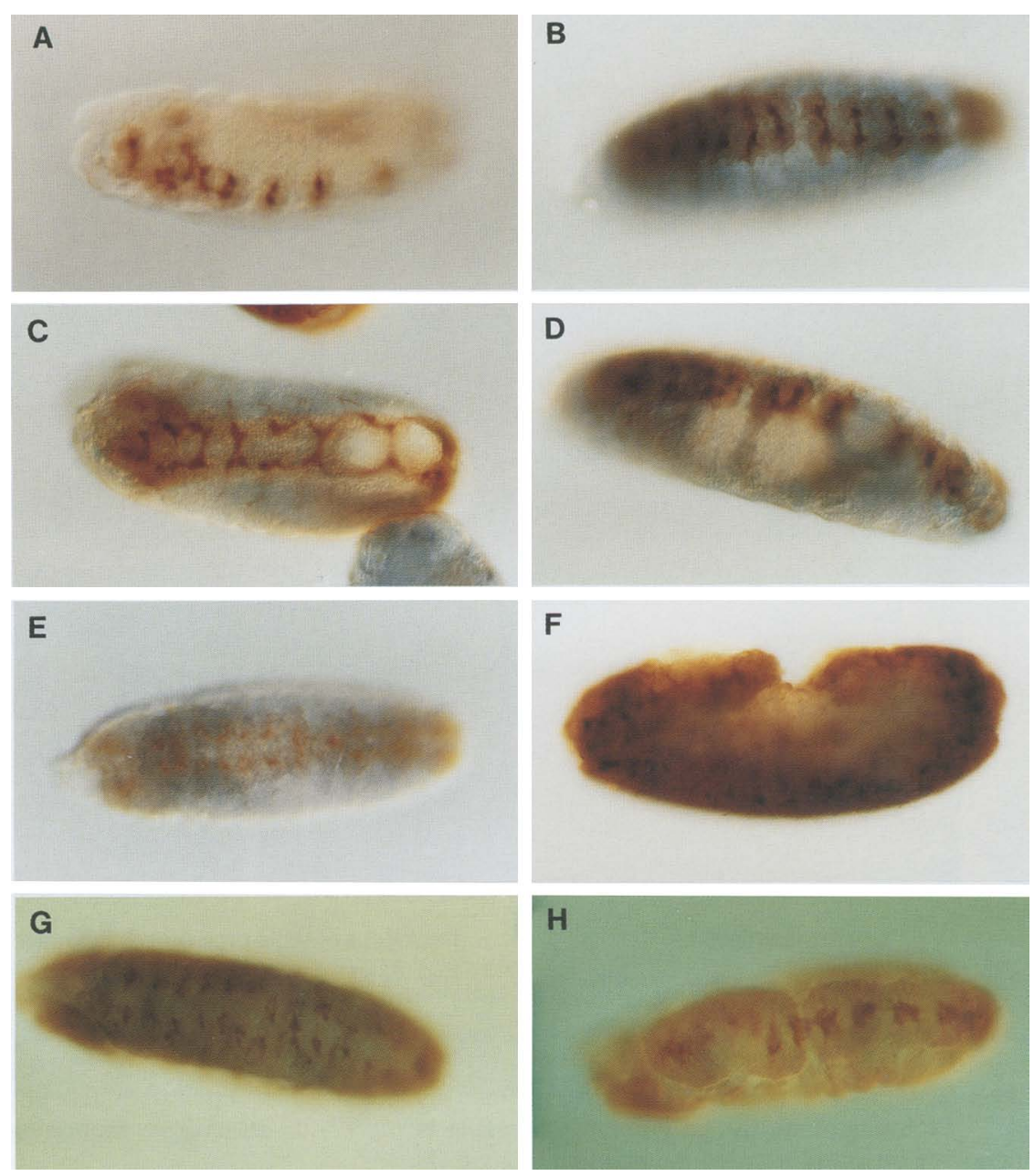
peats, would be involved in producing Delta-independent activation of the Notch protein.

The second route for determining whether the antineurogenic phenotype of $\mathrm{N}^{\Delta \mathrm{LN}}$ rpts requires Delta involved expression of the construct in $\mathrm{Dl}^{-}$embryos. The $D 1$ allele used $\left(D 1^{X}\right)$ acts as a null mutation and produces an extreme neurogenic phenotype (Lehmann et al. 1983). Figure $7 \mathrm{~B}$ shows that, as expected from the behavior of $\mathrm{N}^{\Delta(E G F 1-18 \text { and LN rpts) }}$ above, $\mathrm{N}^{\Delta \mathrm{LN} \text { rpts }}$ suppresses the neurogenic phenotype expected for $\mathrm{Dl}^{-}$embryos, and, to some degree, the antineurogenic phenotype promoted by $\mathrm{N}^{\Delta \mathrm{LN}}$ rpts protein persists in $\mathrm{Dl}^{-}$embryos. Therefore, Delta protein may be capable of binding to $\mathrm{N}^{\Delta \mathrm{LN} \text { rpts }}$ in vivo, but such an interaction is not required for the functional activity of this altered Notch protein.

The third class of antineurogenic proteins was derived by substitution of serines for the cysteines proposed to be responsible for dimer formation. The antineurogenic phenotype generated by $\mathrm{N}^{\mathrm{c} 1693>\mathrm{s}}$ is not observed in the $\mathrm{DI}^{-}$background (Table 1). Thus, at some level the mechanisms for generating the antineurogenic phenotypes must differ.

The antineurogenic phenotype resulting from deletion of the lin $12 / \mathrm{N}$ repeats $\left(\mathrm{N}^{\Delta \mathrm{LN} \text { rpts}}\right)$ was observed in neuralized, mastermind, and bigbrain mutant backgrounds (Table 1; Fig. 7C-E). The neuralized mutation used $\left(n e u^{I F 65}\right)$ produces an extreme neurogenic phenotype and is presumably a null allele (Lehmann et al. 1983). All bigbrain mutations isolated to date $\left(b_{i b} b^{A 5156}\right.$ was used in this study/ are believed to be null alleles and produce an intermediate neurogenic phenotype as does the mastermind allele used, mam $^{I 113}$ (Lehmann et al. 1983). Thus, the $\mathrm{N}^{\Delta \mathrm{LN} \text { rpts }}$ Notch mutation is epistatic to loss or lowered function mutations at four of five neurogenic loci examined. $E(s p l)^{-}$was epistatic to the Notch mutation: $\mathrm{N}^{\Delta \mathrm{LN} \text { rpts }}$ cannot produce an antineurogenic phenotype in $E(s p 1)^{-}$embryos, nor suppress the neurogenic pheno-

Table 1. CNS phenotypes produced by Notch gain-of-function proteins in neurogenic backgrounds

\begin{tabular}{lcccccc}
\hline & $\mathrm{N}$ & $\mathrm{Dl}$ & neu & mam & bib & E(spl) \\
\hline $\mathrm{N}^{\Delta \mathrm{LN} \text { rpts }}$ & + & + & + & $+/-$ & + & - \\
$\mathrm{N}^{\text {c1693>s }}$ & + & - & - & N.D. & $+/-$ & - \\
$\mathrm{N}^{\text {c1696>s }}$ & + & N.D. & - & N.D. & $+/-$ & - \\
$\mathrm{N}^{\text {c1693>s,c1969>s }}$ & + & N.D. & N.D. & N.D. & N.D. & N.D. \\
$\mathrm{N}^{\text {Intracellular }}$ & N.D. & N.D. & + & N.D. & N.D. & - \\
\hline
\end{tabular}

Transgenic strains expressing the mutant Notch proteins were crossed into various mutant backgrounds. Homozygous and hemizygous mutant embryos were identified by lack of reactivity with anti- $\beta$-gal antibody (see Materials and methods). CNS phenotypes were determined using anti-HRP antibody (see text, Materials and methods, and Figs. 6 and 7). (N) $N^{264-47}$; (Dl) $D 1^{X}$; (neu) neu ${ }^{I F 65}$; (mam) mam ${ }^{I 113}$; (bib) bib ${ }^{A 5156}$; [E(spl)] $E(s p l)^{R 1}$. For a description of the mutants, see text and Lindsley and Zimm (1992). $(+1$ The antineurogenic phenotype was observed in homozygous or hemizygous mutants; $(-)$ the antineurogenic phenotype was not observed; $(+1-)$ whereas a strong antineurogenic phenotype was not observed, there was suppression of the neurogenic phenotype. (N.D.) Not determined. type generated by $E(s p I)^{-}$mutation (Table 1$)$. Therefore, the antineurogenic phenotype of $\mathrm{N}^{\Delta \mathrm{LN} \text { rpts }}$ is dependent on the presence of some or all of the genes of the $E(s p l)$ complex and/or gro. [The $E(s p l)$ mutation used, $E(s p l)^{R 1}$, is a chromosomal rearrangement that eliminates all of these genes (Preiss et al. 1988; Ziemer et al. 1988) and results in a strong neurogenic phenotype (Lehmann et al. 1983)]. The $E(s p l)$ mutation also was not suppressed by expression of $\mathrm{N}^{\text {Intracellular domain }}$, and $E(s p l)^{R 1}$ blocked the antineurogenic activity of $\mathrm{N}^{\text {Intracellular domain }}$ protein $(\mathrm{Ta}$ ble 1, Fig. 7F).

As mentioned above, Delta is required for manifestation of the antineurogenic phenotype resulting from expression of Notch mutated for cysteine 1693 (Table 1). As shown in Table 1, $\mathrm{N}^{\text {c1693>s }}$ was tested in three additional mutant backgrounds [E(spl), neu, and bib (alleles described above)]. Like $\mathrm{N}^{\text {Intracellular domain }}$ and $\mathrm{N}^{\Delta \mathrm{LN} \text { rpts }}$, $\mathrm{N}^{\mathrm{c} 1693>\mathrm{s}}$ failed to rescue the neurogenic phenotype produced by $E(s p l)$ mutant embryos, and rescued the neurogenic phenotype associated with $b i b$. Although a strong antineurogenic phenotype was not manifest in $\mathrm{bib}^{-} \mathrm{em}$ bryos, the hypertrophy of the nervous system was reduced (Fig. 7G-H, cf. also to behavior of $\mathrm{N}^{\Delta \mathrm{LN}}$ rpts in $b_{i b}^{-}$embryos, Fig. 7D|. In contrast to the other two classes of antineurogenic Notch proteins, $\mathrm{N}^{\mathrm{c} 1693>\mathrm{s}}$ failed to modify the neurogenic phenotype produced by the neu mutation. Again, as in the response of this protein to Delta mutation, the results suggest some differences in the mechanisms behind the antineurogenic phenotypes produced by the different classes of truncated Notch proteins.

\section{Discussion}

\section{Gain-of-function Notch mutations}

We have identified three ways by which embryonic, gain-of-function antineurogenic phenotypes can be generated at Notch. Two of these involve changes in the external domain: deleting the lin $12 / \mathrm{N}$ repeats or mutating the cysteines thought to be responsible for dimer formation. The third route involves expressing the cytoplasmic domain untethered to the membrane. One of the three classes of antineurogenic mutations, the cysteine changes, are ligand dependent; that is, the antineurogenic phenotype is dependent on the presence of Delta. In contrast, the antineurogenic phenotype resulting from expression of protein lacking the lin $12 / \mathrm{N}$ repeats $\left(\mathrm{N}^{\Delta \text { LN rpts }}\right)$ is still manifest in the absence of the Deltabinding site of Notch and in the absence of Delta. Of course, the cytoplasmic domain ( $\mathrm{N}^{\text {Intracellular domain }}$ ) lacks the extracellular domain containing the Deltabinding site altogether.

Modifications that result in gain-of-function phenotypes have also been associated with Notch homologs in other organisms (Greenwald and Seydoux 1990; Ellisen et al. 1991; Jhappan at al. 1992; Coffman et al. 1993). In particular, a dominant gain-of-function phenotype can be generated in Xotch, the Xenopus Notch homolog, by deleting most of the extracellular domain /Coffman et al. 
1993). The construct we generated lacking the EGF and lin $12 / N$ repeats $\left[N^{\Delta(E G F}\right.$ and $L N$ rpts) $]$ did not behave in a similar fashion. Our construct, in contrast to Xotch $\Delta \mathrm{E}$, included the cysteines thought to be involved in dimer formation, suggesting that formation of dimers is important for the appropriate regulation of Notch. int 3 , which is activated in mouse mammary tumors by insertion of the mouse mammary tumor virus and has homology to the cytoplasmic domain of Notch (Jhappan et al. 1992; Robbins et al. 1992) and a translocation that removes most of the extracellular domain (34 EGF-like repeats) of the human Notch homolog, TAN-1 (Ellisen et al. 1991), also may produce gain-of-function activities through expression of proteins resembling $\mathrm{N}^{\text {Intracellular domain }}$.

\section{Notch in the context of other neurogenic genes}

de la Concha et al. (1988) have examined the effect of increasing the dosage of individual wild-type neurogenic genes on the neurogenic phenotype generated by loss of other neurogenic genes. They have generated a network of proposed functional interactions that suggests a common pathway for the action of the neurogenic genes with the exception of bib. There is also additional genetic evidence that suggests a functional interaction between the gene products of $N, D l$, mam, and $E$ (spl) (Welshons 1956; Shepard et al. 1989; Xu et al. 1990). We have used our gain-of-function Notch mutations to examine where Notch fits in this network. The antineurogenic phenotype generated by expression of the $\mathrm{N}^{\Delta \mathrm{LN}}$ rpts protein is still manifest in $D l, n e u, b i b$, and mam, embryos. Thus, activated Notch can compensate for loss of products encoded by these genes. One likely explanation is that products expressed by $D l$, neu, bib, and mam function upstream of Notch and are involved in generation of the signal that leads to activated Notch protein. However, some of our observations suggest that the pathway formed by the neurogenic genes may not be strictly linear. Rather, at least some proteins could have multiple roles (or inputs) in the network. For example, the antineurogenic phenotype produced by $\mathrm{N}^{\Delta \mathrm{LN} \text { rpts }}$ protein in these mutant backgrounds was not as strong as that generated in either wild-type or $N$ embryos. Neither was the antineurogenic phenotype generated by expression of the $\mathrm{N}^{\Delta \mathrm{LN} \text { rpts }}$ protein in $D I$ embryos as strong as that generated by $\mathrm{N}^{\Delta \text { (EGF } 1-18 \text { and } L N ~ r p t)}$ in a $\mathrm{Dl}^{+}$background (Fig. 7, cf. A with B). In addition, in mam embryos carrying $\mathrm{N}^{\Delta \mathrm{LN}}$ rpts it appeared as though we were observing a combination of neurogenic and antineurogenic phenotypes (Fig. 7E). In spite of these caveats, we feel the simplest interpretation of the results continues to be that much of the function of neu, Delta, mam and bib occurs upstream of Notch.

It had been proposed previously that bib acts independently of the other neurogenic genes (de la Concha et al. 1988; Xu et al. 1990). Nevertheless, $\mathrm{N}^{\Delta \mathrm{LN} \text { rpts }}$ was epistatic to a bib mutation, and the neural hypertrophy associated with bib deficiency was reduced by mutations of the cysteines thought to be responsible for Notch dimerization $\left(\mathrm{N}^{\mathrm{c} 1693>\mathrm{s}}\right.$ and $\mathrm{N}^{\mathrm{c} 1696>\mathrm{s}}$; Table 1). Although the results are consistent with a role for bib upstream of Notch, alternatively bib, or any of the neurogenic genes, could be participating in separate but functionally redundant pathways, such that production of activated Notch can compensate partially for loss of another neurogenic gene product.

Interestingly, although expression of Notch proteins with the described cysteine changes $\left(\mathrm{N}^{\mathrm{c} 1693>\mathrm{s}}\right.$ and $\mathrm{N}^{\mathrm{c} 1696>\mathrm{s}}$ / can rescue bib mutation at least partially, the mutant Notch proteins have no effect on the neural hypertrophy associated with $\mathrm{Dl}$ or neu. If bib, neu, mam, and $D l$ are all involved in elaboration of a Notch-activating signal as proposed, then unlike $\mathrm{N}^{\Delta \mathrm{LN} \text { rpts}}$, Notch proteins with these cysteine substitutions must continue to require the action of some upstream neurogenic genes to produce activated Notch. A further investigation of the different activities associated with $\mathrm{N}^{\Delta L N}$ rpts, $\mathrm{N}^{\text {c1693>s }}$, and $\mathrm{N}^{\mathrm{c1696}>\mathrm{s}}$ may elucidate the molecular mechanism by which wild-type Notch protein is activated.

\section{Does Notch function in nuclei?}

When the cytoplasmic domain of Notch is not tethered to the membrane ( $\mathrm{N}^{\text {Intracellular domain }}$ ), it can be found in the nucleus and an antineurogenic phenotype is produced. The nuclear localization is surprising because Notch has never been found in the nucleus in wild-type flies. Moreover, no Notch immunoreactivity was found in the nucleus of flies expressing the $\mathrm{N}^{\Delta L N}$ rpts protein, although the latter produces an antineurogenic phenotype that is comparable with that seen for $\mathrm{N}^{\text {Intracellular domain }}$. Thus, detectable nuclear localization of Notch is not essential for generation of the antineurogenic phenotypes. If some membrane-linked Notch proteins can produce antineurogenic phenotypes, nuclear localization of $\mathrm{N}^{\text {Intracellular domain }}$ may be artifactual, that is, Notch may always be inserted in the membrane such that the NLSs in the cytoplasmic domain are never functional. If this were the case, the nuclear localization observed for $\mathrm{N}^{\text {Intracellular domain }}$ might be passive and play no role in the mechanism behind this protein's antineurogenic activity.

Alternatively, a segment of Notch might normally enter and function in the nucleus after cleavage of the transmembrane protein but be overlooked if its stability were tightly regulated. In particular, nuclear localization would be difficult to detect if Notch function were linked to rapid turnover of a processed Notch cytoplasmic domain. One observation supports such a hypothesis. After heat shock the soluble cytoplasmic domain might be expected to be distributed uniformly in all nuclei of any given tissue. Yet, differences in nuclear accumulation were observed for $\mathrm{N}^{\text {Intracellular domain }}$ (see Fig. 4). For example, in larval brains Hoechst staining (not shown/ reveals a wide band of densely packed nuclei that is just medial to the heavily Notch-expressing region in wild-type brains shown in Fig. 4D. The cytoplasmic domain of Notch accumulates to only low levels in this region (Fig. 4, cf. D and E). Although it is possible that differences in nuclear labeling reflect differ- 
ences in levels of protein synthesis, it is intriguing that $\mathrm{N}^{\text {Intracellular domain }}$ also is abundant in the polytene nuclei of terminally differentiated salivary glands and fat body, and in the nuclei of diploid neuroblasts of the brain, and thoracic and abdominal ganglia. Cells comprising the salivary glands and fat body of third-instar larvae do not normally express detectable levels of Notch (Kidd et al. 1989; Fehon et al. 1991), which suggests that these cells do not require active Notch protein to survive and function. Although larval neuroblasts do express Notch at the developmental stage examined (Kidd et al. 1989; Fehon et al. 1991), Notch function is not required for a cell to be a neuroblast. The progeny of the neuroblasts, the ganglion mother cells (GMCs), and the bulk of cells in the brain and ganglion, accumulate $\mathrm{N}^{\text {Intracellular domain }}$ to lower levels than neuroblasts. The GMCs normally express Notch at levels comparable with or higher than neuroblasts (Kidd et al. 1989; Fehon et al. 1991).

Given that most of the cells in the brain express Notch to some degree (Kidd et al. 1989; Fehon et al. 1991) and may require Notch to differentiate correctly [e.g., facet alleles, which are intronic, hypomorphic mutations of Notch, exhibit optic lobe defects (Markopolou et al. 1989 )], the low levels of $\mathrm{N}^{\text {Intracellular domain }}$ accumulating in many brain cells as compared with neuroblasts could indicate that in cells where Notch is required $\mathrm{N}^{\text {Intracellular domain }}$ is degraded. Possibly, in wild-type flies and in flies carrying the $\mathrm{N}^{\Delta L N}$ rpts construct, absence of Notch protein in the nucleus of cells thought to require Notch activity simply refects its rapid degradation in these nuclei. In particular, although the $\mathrm{N}^{\Delta \mathrm{LN} \text { rpts }}$ construct would express high levels of constitutively active Notch, if the protein were processed, the rate of entry of a derivative cytoplasmic domain into the nucleus should depend on the rate of processing by a protein only present at normal levels.

We have identified two putative NLSs in Drosophila Notch at amino acids $1832-1835$ and amino acids 22022205. Notch polypeptides containing these sequences can translocate $\beta$-gal into the nucleus in cultured Drosophila cells. The significance of the nuclear associations of $\mathrm{N}^{\text {Intracellular domain }}$ could be tested by assaying Notch activity in flies lacking these sequences. For example, it might be expected that deletion of the putative NLSs would render $\mathrm{N}^{\text {Intracellular domain }}$ ineffective in promoting an antineurogenic phenotype, and the same deletion in full-length Notch (e.g., $\mathrm{N}^{\mathrm{hsN}}$ ) should result in loss of function for that protein. These investigations are in progress. Because $\mathrm{N}^{\triangle \mathrm{BAM} / \mathrm{RV}}$, which deletes the second putative Notch NLS (Fig. 5A), can rescue $N^{-}$embryos in our assays, this sequence is not essential, but the NLSs mapped in vitro may provide redundant function. One might assume that any mechanism proposed for action of Drosophila Notch would apply to Notch homologs in other organisms; therefore, the homolog would retain NLSs. Sequences corresponding to NLS1 and NLS2 (Fig. 5A) are found in Xotch (Coffman et al. 1990), in the mouse homolog, Motch (Franco del Amo et al. 1992), in both rat Notch proteins (Weinmaster et al. 1991; Wein- master et al. 1992), and in Tan-1 (Ellisen et al. 1991). A second human Notch, hN, contains at least sequences composing NLS2 (the reported sequence is incomplete; Stifani et al. 1992). The C. elegans protein lin-12 (Yochem et al. 1988) contains NLS1, but a second Notchrelated protein, glp-1 (Yochem and Greenwald 1989), contains neither. Thus, it will be important to determine whether cytoplasmic glp-1 promotes nuclear localization as with $\mathrm{N}^{\text {Intracellular domain }}$.

If wild-type Notch were processed to provide a nuclear-active protein, the function of any binding of ligand, such as Delta, might be an alteration of the conformation of the cytoplasmic domain so that it is accessible to proteolytic cleavage. Modified Notch proteins that give antineurogenic phenotypes might also influence such a process. Deletion of the lin $12 / \mathrm{N}$ repeats might produce an appropriate conformational change independent of Delta binding. Mutation of cysteines 1693 or 1696 , or both, could give a protein that while still requiring activation by ligand, has bypassed another required activation step.

\section{Functional dissection of the cytoplasmic domain}

Our results indicate that the cytoplasmic domain of Notch, independently expressed, can influence cell fate in a manner like that expected for activated, full-length Notch protein. The cdcl0 repeats are essential for the activity of any of the Notch proteins we examined that span the membrane. $\mathrm{N}^{\Delta C D C 10}$ rpts cannot promote epidermal rescue, nor does expression of $\mathrm{N}^{\Delta(\mathrm{LN} \text { and cdc10 rpts) }}$ or $\mathrm{N}^{\text {cys1693>s and } \Delta \mathrm{cdcl0} \text { rpts }}$ result in an antineurogenic phenotype. In C. elegans, a lin12(0) mutation has also been mapped to the cdc10 repeats (Greenwald and Seydoux 1990). Mutations affecting in vivo function have also been mapped to the cdc10 repeats of cactus (S.K., unpubl.) and $c d c 10$ (Reymond et al. 1992). In other proteins, cdc10 repeats have been demonstrated to mediate protein-protein interactions (for review, see Kidd 1992); therefore, we would expect this region of Notch to allow specific protein association as well.

The carboxyl terminus contains a putative PEST sequence. PEST sequences are associated with high rates of turnover (Rogers et al. 1986). This might be the function of this region as $\mathrm{N}^{\text {Intracellular domain }}$ appears to be degraded rapidly in some cell types. We have preliminary evidence that this region is required for Notch function, as $\mathrm{N}^{\Delta C T}$ (deletes carboxy-terminal 130 amino acids) cannot rescue the cuticle phenotype of $N^{-}$embryos. Also the hypomorphic mutation $n d^{2}$ affects this region of Notch. $n d^{2}$ produces a frameshift that changes the 14 carboxyterminal amino acids (Xu et al. 1990).

In our assays the strep/opa (polyQ) sequence, appears to be nonessential. Comparison of Drosophila Notch and related proteins from other species also indicates no strict requirement for these sequences. Although Drosophila Notch has 30 glutamines in this region (Wharton et al. 1985; Kidd et al. 1986), Tan-1 has 16 (Ellisen et al. 1991 ), hN has 3 (Stifani et al 1992), rat Notch 1 has 10 (Weinmaster et al. 1991), rat Notch 2 has 3 (Weinmaster 
et al 1992), Xotch has 12 (Coffman et al. 1990), and lin-12 (Yochem et al. 1988) and glp-1 (Yochem and Greenwald 1989) have no detectable homology to Drosophila Notch in this region. Although our assays have not detected an essential role for the strep/opa sequence of Notch, glutamine-rich domains have been identified in a variety of other proteins both in Drosophila and in other organisms, and these sequences can behave as transcriptional activators (Mitchell and Tjian 1989). As an example, polyglutamine sequences are essential for the activating ability of the transcription factor SP1 (Courey and Tiian 1988). In light of our analysis of strep/opa in Notch, it may be important that deletion of a comparable polyglutamine region in the homeo domain protein Antennapedia also seems to have little affect on function (Gibson et al. 1990). From its location and structure, the Antennapedia polyglutamine sequence was predicted originally to have a role in that transcription factor's function analogous to poly(Q) in SP1 (Gibson et al. 1990).

Other features of the cytoplasmic domain allow further comparison with activator proteins. The amino half of the domain, including the cdcl0 repeats, is rich in charged residues (Mitchell and Tjian 1989), and its carboxy-terminal region is rich in serine and threonine as is the poly $(\mathrm{Q})$-adjacent region of SP1/Courey and Tjian 1988). It is intriguing that the region encompassing the cdcl0 repeats and the charged region, along with possibly the carboxyl terminus, may be all that is required for the antineurogenic phenotype. Perhaps the remaining sequences only modulate levels of Notch activity. A recent study of the $N^{60 g 11}$ mutation of Drosophila supports the same conclusion (Lyman and Young 1993). This mutation affects the structure of an endogenous Notch gene, therefore, the affected protein is expressed under the control of the Notch promotor with appropriate developmental specificity. The $N^{60811}$-encoded protein contains all extracellular Notch sequences, the transmembrane domain, and the Notch cdc10 repeats but is deficient for all sequences thereafter. The truncated protein not only provides some Notch activity during imaginal development but, in some differentiating imaginal cell types, appears to supply hyperactive function (Lyman and Young 1993).

All of our antineurogenic phenotypes are dependent on the expression of the $E(s p l)$ complex or gro, or both. Thus, these genes act downstream of or in conjunction with Notch. Many of the $E(s p l)$ genes encode basic-helix-loop-helix (bHLH) transcription factors (Knust et al. 1992; Schrons et al. 1992), and gro encodes a protein with WD40 repeats that are thought to mediate transcriptional repression (Hartley et al. 1988; Keleher et al. 1992; Stifani et al. 1992). The neurogenic genes, including the $E(s p l)$ complex, behave as repressors of the activity of the proneural genes, which are in turn required for neuroblast formation. For example, in embryos deficient for a neurogenic gene, an abnormal expansion of the pattern of AS-C gene expression has been observed. Expression of at least some AS-C genes does not become restricted to one cell of the equivalence group as would be expected for wild-type (Brand and Campos-Ortega 1988; Skeath and Carroll 1992; Ruiz-Gomez and Ghysen 1993). Perhaps Notch activates the $E(s p l)$ complex whereas the latter represses activity of the proneural genes directly, including genes of the AS-C. Although we have pointed to several features that may link Notch and certain transcriptional activators, Notch lacks one characteristic often associated with such proteins; it has no obvious homology to known DNA-binding proteins. A nuclear Notch protein might, however, be tethered to DNA by interaction with a DNA-binding protein. For example, Bcl-3 cannot bind DNA alone but can activate transcription by its association with $\mathrm{p} 50$. The interaction of $\mathrm{Bcl}-3$ with p50 is mediated by its cdc10 repeats (Bours et al. 1993). The cytoplasmic domain of Notch, if it is processed for nuclear entry, appears to be degraded rapidly, therefore, as an alternative to transcriptional activation, perhaps the function of Notch is to transport a protein to the nucleus where it is then degraded, releasing the protein it has transported. All of this is speculation, however, and the function of Notch if any in the nucleus remains an enigma.

\section{Materials and methods}

\section{Constructs}

P-element transformations The Notch minigene encoding the full-length Notch protein has been described previously (Lieber et al. 1992). All other constructs used to generate the transgenic Drosophila lines were derivatives of this minigene. In the following description of the construct generations, the nucleotide numbers are derived from Kidd et al., (1986). $\Delta \mathrm{I}$ : The NruI site at nucleotide 14,441 was fused to the $P f / m I$ site at nucleotide 17,253. $\triangle$ CDC10 rpts: PCR was used to add a BamHI site to the NruI site at nucleotide 14,441 according to the method of Innis et al., (1990). This BamHI site was then ligated to the BamHI site at nucleotide 15,542 . $\Delta$ poly $(Q)$ : The EcoRV site at nucleotide 16,843 was fused to the StuI site at nucleotide 16,951 . $\Delta \mathrm{Bam} / \mathrm{RV}$ : The BamHI site at nucleotide 15,542 was fused to the EcoRV site at nucleotide 16,843 . $\Delta \mathrm{CT}$ : The StuI site at nucleotide 16,951 was fused to the SacII site at nucleotide 17,521 . $\triangle \mathrm{EGF}(1-36)$ : PCR was used to add a Bsu36I site after nucleotide 1567, which was then ligated to a $B a m H I$ site at nucleotide 13,469. $\triangle E G F(1-18)$ : Two separate PCR products with overlapping sequence were combined into one longer product, according to the method of Innis et al., (1990), such that nucleotide 1565 was fused to nucleotide 11,336. $\triangle \mathrm{EGF}(19-36)$ : PCR was used to add a $B a m H I$ site after nuclotide 11,335 , which was then ligated to a BamHI site at nucleotide 13,469 . $\Delta$ LN rpts: A BamHI linker was added to the Bsu36I site at nucleotide 13,948. This $B a m H I$ site was then ligated to the BamHI site at nucleotide 13,469 . $\triangle E G F$ and $\triangle L N$ rpts: PCR was used to add a Bsu36I site after nucleotide 1567, which was then ligated to a Bsu36I site at nucleotide 13,948. All PCR generated fragments were sequenced. $\mathrm{N}^{\mathrm{c1693}>\mathrm{s}}, \mathrm{N}^{\mathrm{c1696>s}}$, and $\mathrm{N}^{\mathrm{c1693>s,c1696>s}}$ were generated using site-directed mutagenesis following the procedure supplied by Amersham (Oligonucleotide-Directed In Vitro $\mathrm{Mu}$ tagenesis System RPN.1523). The doubly mutant constructs were generated by combining singly mutant ones. To generate $\mathrm{N}^{\text {Intracellular domain }}$, we required a $5^{\prime}$ untranslated region and initiating methionine. Therefore, $\mathrm{N}^{\text {Intracellular domain }}$ was produced by adding a BamHI linker to the NruI site at nucleotide 14,441 and ligating this to the BamHI site that follows the oligonucleotide encoding the flag epitope in a cactus-flag con- 
struct (Kidd 1992). The 5' untranslated region and the first 2 amino acids are derived from cactus (nucleotides 21-158 of cactus; Kidd 1992). The full-length Notch minigene with an hsp70 promoter (Lieber, et al. 1992) was subcloned into Carnegie 20 (Rubin and Spradling 1983). All other constructs were subcloned into pCaSpeR-hs (Thummel and Pirrotta 1992). Western blot analysis was used to verify that all transformants express Notch proteins of the expected sizes upon heat shock.

S2 cells Expression plasmids for Drosophila cells were constructed by cloning the actin sequences from pCaSpeR-actB (Thummel et al. 1988) between the BssHI sites of Bluescript $\mathrm{SK}^{-}$and then cloning the Bluescript polylinker and adjacent $\mathrm{T} 3$ and T7 RNA polymerase sites as a BssHI fragment between the actin promoter and terminator sequences. $\beta$-Gal constructs under the control of the actin promoter contain the $5^{\prime}$ half of the lac $Z$ gene from pCaSpeR-AUG- $\beta$-gal (Thummel et al. 1988) and the remaining sequences isolated from pUR292 (Ruther and Muller-Hill 1983) cloned in the polylinker of the plasmids described above.

\section{Antibodies}

The anti-HRP antibody was a rabbit polyclonal antibody (Jackson Labs). The anti- $\beta$-gal antibody was a mouse monoclonal antibody (Promega). Two anti-Notch antibodies were used. For detection of Notch in S2 cells (Fig. 5), antibody directed against T7 fusion protein (Studier et al. 1990), containing amino acids 1795-2157 of Notch, was raised in rabbits. For localization of Notch in vivo, plasmids expressing amino acids 2115-2536 of Notch under control of the T7 promoter in Escherichia coli were constructed by using PCR to amplify the corresponding Notch cDNA and cloning this into pET14b. Protein was then isolated using $\mathrm{Ni}^{2+}$ affinity columns as described by the manufacturer (Invitrogen). This protein was then used to raise antisera in mice as described previously (Kidd 1992).

\section{Immunocytochemistry and cuticle preparations}

S2 cells Drosophila Schneider line 2 cells were transfected as described (Ashburner 1989). Proteins were localized as described previously (Lieber et al. 1992) using a biotinylated secondary antibody (Vector) and AMCA-conjugated streptavidin (Vector).

Embryos Embryos were collected for $2 \mathrm{hr}$, aged for $3 \mathrm{hr}$ at $25^{\circ} \mathrm{C}$, heat-shocked at $37^{\circ} \mathrm{C}$ for $1 / 2 \mathrm{hr}$, aged for $4 \mathrm{hr}$ at $25^{\circ} \mathrm{C}$ and heat-shocked again for $1 / 2 \mathrm{hr}$. For antibody staining, embryos were fixed (Kidd et al. 1989) at stages 15-16. Anti-HRP antibody was visualized using a peroxidase Vectastain $A B C$ kit (Vector). For double labeling, anti- $\beta$-gal antibody was visualized using an alkaline phosphatase Vectastain ABC-AP kit (Vector). The embryos were then washed and incubated with anti-HRP antibody that was visualized using biotinylated antirabbit antibody (Vector) and peroxidase-conjugated streptavidin (Vector). Cuticle preparations were done as described (Roberts 1986). Immunocytochemistry using anti-HRP antibody in $\mathrm{N}^{+}$backgrounds was performed on the following numbers of independently gener-

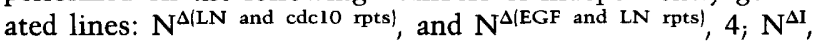
$\mathrm{N}^{\Delta \text { polyQ }}, \mathrm{N}^{\Delta \mathrm{LN} \text { rpts }}, \mathrm{N}^{\mathrm{c1693}>\mathrm{s}, \mathrm{cl} 1696>\mathrm{s}}$, and $\mathrm{N}^{\mathrm{c} 1693>\mathrm{s} \text { and } \Delta \text { cdc10 rpts, }}$ $3 ; \mathrm{N}^{\Delta \mathrm{CT}}, 1$; all other lines, 2 . The same numbers of independently generated lines were used for cuticle preparations, with the exception of $\mathrm{N}^{\text {Intracellular domain }}$ for which only one line was examined. For each line $\geqslant 100$ embryos were examined. The images presented are representative of what was observed.

Larvae Larvae were heat-shocked for $1 / 2 \mathrm{hr}$ at $37^{\circ} \mathrm{C}$ and allowed to recover for $2 \mathrm{hr}$ at $25^{\circ} \mathrm{C}$. The brains and salivary glands of third-instar larvae were isolated and analyzed by immunocytochemistry as described previously (Kidd et al. 1989).

\section{Acknowledgments}

We thank Ralph Greenspan for the w arm ${ }^{\text {YD35 }} N^{X K 11} /$ FM7 fly strain. This work was supported by a grant from the National Institutes of Health to M.W.Y. (GM25103). M.W.Y. is an investigator with the Howard Hughes Medical Institute (HHMI). E.A. was supported by HHMI.

The publication costs of this article were defrayed in part by payment of page charges. This article must therefore be hereby marked "advertisement" in accordance with 18 USC section 1734 solely to indicate this fact.

\section{References}

Ashburner, M. 1989. Drosophila: A laboratory manual. Cold Spring Harbor Laboratory Press, Cold Spring Harbor, New York.

Basler, K., B. Christen, and E. Hafen. 1991. Ligand-independent activation of the sevenless receptor tyrosine kinase changes the fate of cells in the developing Drosophila eye. Cell 64: 1069-1081.

Bours, V., G. Franzoso, V. Azarenko, S. Park, T. Kanno, K. Brown, and U. Siebenlist. 1993. The oncoprotein Bcl-3 directly transactivates through $\mathrm{kB}$ motifs via association with DNA-binding p50B homodimers. Cell 72: 729-739.

Brand, M. and J.A. Campos-Ortega. 1988. Two groups of interrelated genes regulate early neurogenesis in Drosophila melanogaster. Wilhelm Roux's Arch. Dev. Biol. 197: 457-470.

. 1990. Second-site modifiers of the split mutation of Notch define genes involved in neurogenesis in Drosophila melanogaster. Wilhelm Roux's Arch. Dev. Biol. 198: 275285.

Cabrera, C.V. 1990. Lateral inhibition and cell fate determination during neurogenesis in Drosophila: The interaction between scute, Notch and Delta. Development 109: 733-742.

Celis, J.F.de, M. Mari-Beffa, and A. Garcia-Bellido. 1991a. Cellautonomous role of Notch, an epidermal growth factor homologue, in sensory organ differentiation in Drosophila. Proc. Natl. Acad. Sci. 88: 632-636.

- 1991b. Function of trans-acting genes of the achaetescute complex in sensory organ patterning in the mesonotum of Drosophila. Wilhelm Roux's Arch. Dev. Biol. 200: 64-76.

Chelsky, D., R. Ralph, and G. Jonak. 1989. Sequence requirement for synthetic peptide-mediated translocation to the nucleus. Mol. Cell. Biol. 9: 2487-2492.

Coffman, C., W. Harris, and C. Kintner. 1990. Xotch, the Xenopus homolog of Drosophila Notch. Science 249: 1438-1441.

Coffman, C.R., P. Skoglund, W.A. Harris, and C.R. Kintner. 1993. Expression of an extracellular deletion of Xotch diverts cell fate in Xenopus embryos. Cell 73: 659-671.

Corbin, V., A.M. Michelson, S.M. Abmayr, V. Neel, E. Alcamo, T. Maniatis, and M.W. Young. 1991. A role for the Drosophila neurogenic genes in mesoderm differentiation. Cell 67: 311-323.

Courey, A.J. and R. Tjian. 1988. Analysis of Spl in vivo reveals multiple transcriptional domains, including a novel glutamine-rich activation motif. Cell 55: 887-898.

de la Concha, A., U. Dietrich, D. Weigel, and J.A. CamposOrtega. 1988. Functional interactions of neurogenic genes of Drosophila melanogaster. Genetics 118: 499-508. 
Ellisen, L.W., J. Bird, D.C. West, A.L. Soreng, T.C. Reynolds, S.D. Smith, and J. Sklar. 1991. Tan-1, the human homolog of the Drosophila Notch gene, is broken by chromosomal translocations in T lymphoblastic neoplasms. Cell 66: 649661.

Fehon, R.G., K. Johansen, I. Rebay, and S. Artavanis-Tsakonas. 1991. Complex cellular and subcellular regulation of Notch expression during embryonic and imaginal development of Drosophila: Implications for Notch function. I. Cell Biol. 113: 657-669.

Franco del Amo, F., D.E. Smith, P.J. Swiatek, M. GendronMaguire, R.J. Greenspan, A.P. McMahon, and T. Gridley. 1992. Expression pattern of Motch, a mouse homolog of Drosophila Notch, suggests and important role in early postimplantation mouse development. Development 115: 737744.

Ghysen, A., C. Dambly-Chaudiere, L.Y. Jan, and Y.N. Jan. 1993. Cell interactions and gene interactions in peripheral neurogenesis. Genes \& Dev. 7: 723-733.

Gibson, G., A. Schier, P. LeMotte, and W.J. Gehring. 1990. The specificities of Sex combs reduced and Antennapedia are defined by a distinct portion of each protein that includes the homeodomain. Cell 62: 1087-1103.

Greenwald, I. and G.M. Rubin. 1992. Making a difference: The role of cell-cell interactions in establishing separate identities for equivalent cells. Cell 68: 271-281.

Greenwald, I. and G. Seydoux. 1990. Analysis of gain-of-function mutations of the lin-12 gene of Caenorhabditis elegans. Nature 346: 197-199.

Haenlin, M., B. Kramatschek, and J.A. Campos-Ortega. 1990. The pattern of transcription of the neurogenic gene Delta of Drosophila melanogaster. Development 110: 905-914.

Hartenstein, V. and J.A. Campos-Ortega. A. 1986. The peripheral nervous system of mutants of early neurogenesis in Drosophila melanogaster. Wilhelm Roux's Arch. Dev. Biol. 195: 210-221.

Hartenstein, A.Y., A. Rugendorff, U. Tepass, and V. Hartenstein. 1992. The function of the neurogenic genes during epithelial development in the Drosophila embryo. Development 116: 1203-1220.

Hartley, D.A., A. Preiss, and S. Artavanis-Tsakonas. 1988. A deduced gene product from the Drosophila neurogenic locus Enhancer of split shows homology to mammalian G-protein $\beta$ subunit. Cell 55: 785-795.

Heitzler, P. and P. Simpson. 1991. The choice of cell fate in the epidermis of Drosophila. Cell 64: 1083-1092.

- 1993. Altered epidermal growth factor-like sequences provide evidence for a role of Notch as a receptor in cell fate decisions. Development 117: 1113-1123.

Hoppe, P.E. and R.J. Greenspan. 1986. Local function of the Notch gene for embryonic ectodermal pathway choice in Drosophila. Cell 46: 773-783.

- 1990. The Notch locus of Drosophila is required in epidermal cells for epidermal development. Development 109: 875-885.

Innis, M.A., D.H. Gelfand, J.J. Sninsky, and T.J. White. 1990. PCR Protocols: $A$ guide to methods and applications. Academic Press, San Diego, CA.

Jhappan, C., D. Gallahan, C. Stahle, E. Chu, G.H. Smith, G. Merlino, and R. Callahan. 1992. Expression of an activated Notch-related int-3 transgene interferes with cell differentiation and induces neoplastic transformation in mammary and salivary glands. Genes \& Dev. 6: 345-355.

Jimenez, F. and J.A. Campos-Ortega. 1979. A region of the Drosophila genome necessary for CNS development. Nature 282: 310-312.
1990. Defective neuroblast commitment in mutants of the achaete-scute complex and adjacent genes of D. melanogaster. Neuron 5: 81-89.

Johansen, K.M., R.G. Fehon, and S. Artavanis-Tsakonas. 1989. The Notch gene product is a glycoprotein expressed on the cell surface of both epidermal and neuronal precursor cells during Drosophila development. J. Cell Biol. 109: 24272440.

Keleher, C.A., M.J. Redd, J. Schultz, M. Carlson, and A.D. Johnson. 1992. Ssn6-Tup1 is a general repressor of transcription in yeast. Cell 68: 709-719.

Kidd, S. 1992. Characterization of the Drosophila cactus locus and analysis of interactions between cactus and dorsal proteins. Cell 71: 623-635.

Kidd, S., M.R. Kelley, and M.W. Young. 1986. Sequence of the Notch locus of Drosophila: Relationship of the encoded protein to mammalian clotting and growth factors. Mol. Cell. Biol. 6: 3094-3108.

Kidd, S., M.K. Baylies, G.P. Gasic, and M.W. Young. 1989. Structure and distribution of the Notch protein in developing Drosophila. Genes \& Dev. 3: 1113-1129.

Knust, E., H. Schrons, F. Grawe, and J.A. Campos-Ortega. 1992. Seven genes of the Enhancer of split complex of Drosophila melanogaster encode helix-loop-helix proteins. Genetics 132: 505-518.

Kopan, R. and H. Weintraub. 1993. Mouse Notch: Expression in hair follicles correlated with cell fate determination. J. Cell Biol. 121: 631-641.

Kopczynski, C.C., A.K. Alton, K. Fetchel, P.J. Kooh, and M.A.T. Muskavitch. 1988. Delta, a Drosophila neurogenic gene, is transcriptionally complex and encodes a protein related to blood coagulation factors and epidermal growth factor of vertebrates. Genes \& Dev. 2: 1723-1735.

Lehmann, R., F. Jimenez, U. Dietrich, and J.A. Campos-Ortega. 1983. On the phenotype and development of mutants of early neurogenesis in Drosophila melanogaster. Wilhelm Roux's Arch. Dev. Biol. 192: 62-74.

Lieber, T., C.S. Welsley, E. Alcamo, B. Hassel, J.F. Krane, J.A. Campos-Ortega, and M.W. Young. 1992. Single amino acid substitutions in EGF-like elements of Notch and Delta modify Drosophila development and affect cell adhesion in vitro. Neuron 9: 847-859.

Lindsley, D. and G. Zimm. 1992. The genome of Drosophila melanogaster. Academic Press, San Diego, CA.

Lyman, D. and M.W. Young. 1993. Further evidence for function of the Drosophila Notch protein as a transmembrane receptor. Proc. Nat1. Acad. Sci. (in press).

Markopolou, K., W.J. Welshons, and S. Artavanis-Tsakonas. 1989. Phenotypic and molecular analysis of the facets, a group of intronic mutations at the Notch locus of Drosophila melanogaster which affect post embryonic development. Genetics 122: 417-428.

Martin-Bermudo, M.D., C. Martinez, A. Rodriguez, and F. Jimenez. 1991. Distribution and function of the lethal of scute gene product during early neurogenesis in Drosophila. Development 113: 445-454.

Mitchell, P.J. and R. Tjian. 1989. Transcriptional regulation in mammalian cells by sequence-specific DNA binding proteins. Science 245: 371-378.

Preiss, A., D.A. Hartely, and S. Artavanis-Tsakonas. 1988. The molecular genetics of Enhancer of split, a gene required for embryonic neural development in Drosophila. EMBO J. 7: 3917-3927.

Rebay, I., R.J. Fleming, R.G. Fehon, L. Cherbas, P. Cherbas, and S. Artavanis-Tsakonas. 1991. Specific EGF repeats of Notch mediate interactions with Delta and Serrate: Implications 
for Notch as a multifunctional receptor. Cell 67: 687-699.

Reymond, A., S. Schmidt, and V. Simanis. 1992. Mutations in the $c d c 10$ start gene of Schizosaccharomyces pombe implicate the region of homology between cdc10 and SWI6 as important for $\mathrm{p} 85^{c d c 10}$ function. Mol. Gen. Genet. 234: 449456.

Robbins, J., B.J. Blondel, D. Gallahan, and R. Callahan. 1992. Mouse mammary tumor gene int-3: A member of the notch gene family transforms mammary epithelial cells. $J$. Virol. 66: 2594-2599.

Roberts. 1986. Drosophila: A practical approach. IRL Press, Oxford, England.

Rogers, S., R. Wells, and M. Rechsteiner. 1986. Amino acid sequences common to rapidly degraded proteins: The PEST hypothesis. Science 234: 364-368.

Rubin, G.M. and A.C. Spradling. 1983. Vectors for P element mediated gene transfer in Drosophila. Nucl. Acids Res. 11: 6341-6351.

Ruohola, H., K.A. Bremer, D. Baker, J.R. Swedlow, L.Y. Jan, and Y.N. Jan. 1991. Role of the neurogenic genes in establishment of follicle cell fate and oocyte polarity during oogenesis in Drosophila. Cell 66: 433-449.

Ruiz-Gomez, M. and A. Ghysen. 1993. The expression and role of a proneural gene, achaete, in the development of the larval nervous system of Drosophila. EMBO J. 12: 1121-1130.

Ruther, U. and B. Muller-Hill. 1983. Easy identification of cDNA clones. $E M B O$ I. 2: 1791-1794.

Schrons, H., E. Knust, and J.A. Campos-Ortega. 1992. The Enhancer of split complex and adjacent genes in the $96 \mathrm{~F}$ region of Drosophila melanogaster are required for segregation of neural and epidermal progenitor cells. Genetics 132: 481503.

Shepard, S.B., S.A. Broverman, and M.A.T. Muskavitch. 1989. A tripartite interaction among alleles of Notch, Delta, and Enhancer of split during imaginal development of Drosophila melanogaster. Genetics 122: 429-438.

Simpson, P. 1990. Lateral inhibition and the development of the sensory bristles of the adult peripheral nervous system of Drosophila. Development 109: 509-519.

Simpson, P. and C. Carteret. 1990. Proneural clusters: Equivalence groups in the epithelium of Drosophila. Development 110: $927-932$.

Skeath, J.B. and S.B. Carroll. 1992. Regulation of proneural gene expression and cell fate during neuroblast segregation in the Drosophila embryo. Development 114: 939-946.

Stifani, S., C.M. Blaumueller, N.J. Redhead, R.E. Hill, and S. Artavanis-Tsakonas. 1992. Human homologs of a Drosophila Enhancer of Split gene product define a novel family of nuclear proteins. Nature Genetics 2: 119-127.

Studier, F.W., A.M. Rosenberg, and J.J. Dunn. 1990. Use of T7 RNA polymerase to direct expression of cloned genes. Methods Enzymol. 185: 60-89.

Thummel, C.S. and V. Pirrotta. 1992. New pCaSpeR P element vectors. Dros. Inf. Serv. 71: 150.

Thummel, C.S., A.M. Boulet, and H.D. Lipshitz. 1988. Vectors for Drosophila P-element-mediated transformation and tissue culture transfection. Gene 74: 445-456.

Truman, J.W. and M. Bate. 1988. Spatial and temporal patterns of neurogenesis in the central nervous system of Drosophila melanogaster. Dev. Biol. 125: 145-157.

Vassin, H., K.A. Bremer, E. Knust, and J.A. Campos-Ortega. 1987. The neurogenic gene Delta of Drosophila melanogaster is expressed in neurogenic territories and encodes a putative transmembrane protein with EGF-like repeats. $E M B O$ /. 6: 3431-3440.

Weinmaster, G., V.J. Roberts, and G. Lemke. 1991. A homolog of Drosophila Notch expressed during mammalian development. Development 113: 199-205.

- 1992. Notch2: A second mammalian Notch gene. Development 116: 931-941.

Welshons, W.J. 1956. Dosage experiments with split mutants in the presence of an enhancer of split. Dros. Inf. Serv. 30: 157158.

Wharton, K.A., K.M. Johansen, T. Xu, and S. Artavanis-Tsakonas. 1985. Nucleotide sequence from the neurogenic locus Notch implies a gene product that shares homology with protein containing EGF-repeats. Cell 43: 567-581.

Wieschaus, E., C. Nüsslein-Volhard, and G. Jürgens. 1984. Mutations affecting the pattern of the larval cuticle in Drosohila melanogaster. III. Zygotic loci on the X-chromosome and fourth chromosome. Wilhelm Roux's Arch. Dev. Biol. 193: 296-307.

Wieschaus, E. and R. Riggleman. 1987. Autonomous requirements for the segment polarity gene armadillo during Drosophila embryogenesis. Cell 49: 177-184.

$\mathrm{Xu}, \mathrm{T}$., I. Rebay, R.J. Fleming, N.T. Scottgale, and S. ArtavanisTsakonas. 1990. The Notch locus and the genetic circuitry involved in early Drosophila neurogenesis. Genes \& Dev. 4: 464-475.

$\mathrm{Xu}$, T., L.A. Caron, R.G. Fehon, and S. Artavanis-Tsakonas. 1992. The involvement of the Notch locus in Drosophila oognesis. Development 115: 913-922.

Yarden, Y. and A. Ullrich. 1988. Growth factor receptor tyrosine kinases. Annu. Rev. Biochem. 57: 443-478.

Yochem, J. and I. Greenwald. 1989. glp-1 and lin-12, genes implicated in distinct cell-cell interactions in C. elegans, encode similar transmembrane proteins. Cell 58: 553-563.

Yochem, J., K. Weston, and I. Greenwald. 1988. The Caenorhabditis elegans lin-12 gene encodes a transmembrane protein with overall similarity to Drosophila Notch. Nature 335: 547-550.

Ziemer, A., K. Tietze, E. Knust, and J.A. Campos-Ortega. 1988. Genetic analysis of Enhancer of split, a locus involved in neurogenesis in Drosophila melanogaster. Genetics 119: 63-74. 


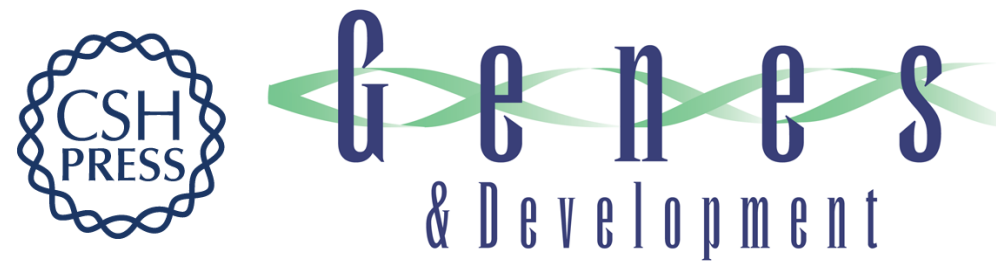

\section{Antineurogenic phenotypes induced by truncated Notch proteins indicate a role in signal transduction and may point to a novel function for Notch in nuclei.}

T Lieber, S Kidd, E Alcamo, et al.

Genes Dev. 1993, 7:

Access the most recent version at doi:10.1101/gad.7.10.1949

References This article cites 75 articles, 33 of which can be accessed free at:

http://genesdev.cshlp.org/content/7/10/1949.full.html\#ref-list-1

License

Email Alerting

Service

Receive free email alerts when new articles cite this article - sign up in the box at the top right corner of the article or click here.

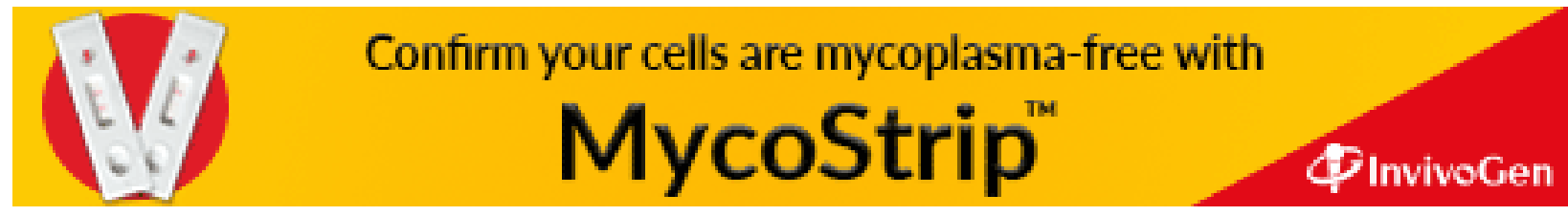

